\title{
22. MEASUREMENTS AND ESTIMATES OF ENGINEERING AND OTHER PHYSICAL PROPERTIES, LEG 19
}

\author{
Homa J. Lee, U. S. Naval Civil Engineering Laboratory, Port Heuneme, California
}

\section{INTRODUCTION}

In order to design structures for the sea floor it is necessary to have some knowledge about how the bottom sediments will behave, in particular, how they will deform after the structure has been placed. The parameters which describe this behavior are identified as engineering properties, and a new field of study, often termed "marine geotechnique," has developed to investigate these properties and their influence. An effort is currently underway to measure engineering properties throughout the world so that ultimately empirical correlations between sediment type and engineering behavior can be developed. The Deep Sea Drilling Project provides a unique opportunity for obtaining data relative to this effort since the distribution of properties over large sediment depth ranges can be determined. These distributions are often easier to correlate with sediment type than are the near-surface property values which can be obtained from tests on conventional cores. As a complicating factor, however, the disturbance produced by drilling is so severe that each piece of measured engineering property data must be critically evaluated in terms of how it relates to the in situ engineering behavior. In most cases a large deviation between laboratory and in situ values will exist. During Leg 19 the physical properties program was expanded to include the measurement of properties which relate to engineering behavior. This was done in full recognition of the role disturbance might play and attempts were made to compensate for this disturbance.

The physical and engineering properties measured on shipboard during Leg 19 were as follows:

1) Natural gamma radiation.

2) Density (by GRAPE and water displacement methods).

3) Water content (from 1-gram syringe samples).

4) Vane shear strength.

5) Residual negative pore water pressure.

6) Acoustic velocity.

At a shore-based laboratory (U.S. Naval Civil Engineering Laboratory) additional physical and engineering properties measured were as follows:

7) Water content (from 10-gram samples).

8) Grain density.

9) Compressibility.

10) Triaxial shear strength (one test).

A brief description of the procedures followed in making these measurements is provided below.

\section{PROCEDURES}

\section{Natural Gamma Radiation}

Natural gamma-ray measurements were made on 1.5 -meter core sections using a scan system based on a design provided by the Marathon Oil Company. This system is described in detail in the Initial Reports of the Deep Sea Drilling Project (Peterson, Edgar et al., 1970). The equipment was removed from the Glomar Challenger in Yokohama to provide additional space in the core lab. Since these readings are no longer being made by DSDP, the Leg 19 measurements are not presented in this volume.

\section{Shipboard Density Measurements \\ GRAPE DENSITY}

The Gamma-Ray Attenuation Porosity Evaluator (GRAPE) was used onboard ship to estimate the wet-bulk density of the Leg 19 cores prior to splitting. The equipment and its use have been described by Evans (1965), Harms and Choquette (1965), and Peterson, Edgar et al. (1970).

The device functions by measuring the attenuation of the intensity of a gamma-ray beam as it passes through a core. For most materials this attenuation is exponentially related to the number of electrons in the path of the gamma-ray beam. Also, for most materials of geologic significance, the ratio of electron density to mass density is approximately constant. Therefore, the amount of gammaray attenuation is nearly proportional to the material mass density as long as the material thickness does not vary.

With these general principles available, it is quite simple to progress from measured gamma-ray attenuation to GRAPE density. The procedure followed on Leg 19 was slightly more involved since it was desired to remove any dependance upon the absolute numbers produced by the equipment. Setting and electronic errors could thereby be removed. The procedure that was followed required that standard aluminum and water samples be run before each core. Since it was known what density values these materials should produce, it was possible to use these readings to calibrate the readings made on cores. The iterative procedure required to accomplish this was executed onshore using a computer and digitized data obtained from the original analog data acquired onboard ship.

The GRAPE densities can be converted into porosities if a grain density is measured or assumed. In this volume the 
GRAPE densities provided in the site summary sections may be converted into porosities using the porosity scale provided at the top of each plot.

\section{WATER DISPLACEMENT DENSITIES}

The firm material at moderate to great sediment depths generally does not fill the core barrels. In some cases a "wafers and paste" structure results in which pieces of relatively undisturbed material are found in a matrix of badly disturbed, almost fluid material. In other cases the "paste" is missing and the core liner is filled with irregularly shaped pieces of material. In these situations, GRAPE density measurements would be in error since the requirement of constant material thickness is not met. It is possible to compensate for these errors by measuring the thickness of the sample pieces and adjusting the GRAPE densities accordingly. This procedure was not used on Leg 19. Instead, large portions of samples (about $1 \mathrm{~kg}$ ) were weighed on a beam balance onboard ship to the nearest 5 grams. These were then submerged in a water-filled graduated cylinder to measure volume to the nearest $5 \mathrm{ml}$. The accuracy resulting from this sort of procedure is about plus or minus 1.5 percent. These data are presented as "water displacement densities" on the site summary density plots.

\section{Shipboard Water Content}

A gimbal-mounted Kahn balance was available aboard the Glomar Challenger for accurately measuring weights less than 1 gram. Small ( 1 to $2 \mathrm{cc}$ ) samples were taken with a calibrated plastic syringe and weighed wet. The samples were then dried at $105^{\circ} \mathrm{C}$ for 24 hours and weighed dry. The water content was calculated using the usual procedure without salt correction. Volume measurements were also made so that porosity and density could be calculated. A comparison of the various density and water content measurements is given in a later section.

\section{Vane Shear Strength}

The U.S. Naval Civil Engineering Laboratory (NCEL) miniature vane shear device was used onboard ship during Leg 19. The device functions in the usual manner (Brand, 1967). A four-bladed vane is inserted into a sediment sample and the vane is torqued until a peak reading is recorded. The shear strength is calculated from the peak torque assuming complete mobilization of she aring resistance over the surface of a cylinder inscribed about the vane. The NCEL vane has the capacity of operating at a variety of rotation speeds, although for Leg 19, the rotation speed of 83 degrees/min was chosen. This speed is significantly higher than the 6 degrees/min usually used in vane shear testing and it has been shown (Migliori and Lee, 1971) that variations in rotation speed of this magnitude can cause changes in measured strength on the order of 10 percent. The faster speed was chosen because it permitted the performance of many more tests and anticipated changes in strength resulting from disturbance (at least 100\%) were much greater than any possible rate effects.

The vane tests were performed with a $1 / 2^{\prime \prime} \times 1 / 2^{\prime \prime}$ vane inserted into samples that had been split. The axis of the vane was perpendicular to the core axis, also a procedure which differs from the norm but which should introduce errors small in comparison with disturbance effects. A presentation and discussion of the vane shear test results is provided in a later portion of this section.

\section{Residual Negative Pore Water Pressure}

For reasons which will be explained later, sediment samples develop pressures in their pore water which are less than atmospheric (negative gage). As will also be discussed later, it is desirable to know the magnitude of these pressures in order to assess the extent of disturbance to which the samples have been subjected. These pressures were measured during Leg 19 using a somewhat standard technique (Gibbs and Coffey, 1969) which required the use of a fine-grained, saturated, ceramic disk. One side of the ceramic disk was connected to a sealed water-filled chamber whose pressure could be monitored with a pressure transducer. The other side of the disk was placed in contact with a sediment surface.

The principle of operation is as follows. The sediment, having an affinity for water by virtue of its negative pore water pressure, attempts to draw water out of the ceramic disk. To achieve this, another fluid (e.g. air) would have to be drawn into the disk to maintain continuity. Since the pore size of the disk is very small, the menisci at the water-air interfaces are strong enough to prevent air intrusion. With water and air flow prohibited, the pressure in the ceramic disk and the sealed chamber are forced to equalize with the pressure in the sediment. It is then possible to make a pressure reading with the transducer.

\section{Acoustic Velocity}

Compressional wave velocities were measured with the Hamilton Frame System which has been described previously (Edgar, Saunders et al., in preparation). All tests were performed on portions of sediment which had been completely removed from the core liner.

\section{Shore Laboratory Water Content}

As a check on the other density measurements, a large number of approximately 10-gram samples were taken aboard ship, sealed, shipped to a shore laboratory (NCEL), and subjected to the usual water content test. Since the samples were sealed in a container within another sealed container, little change in moisture content prior to testing would have been possible.

\section{Grain Density}

For a saturated sediment it is possible to calculate bulk density given only the water content and grain density (Bennett et al., 1971). In order to utilize the 10-gram water content samples for density determination, a number of these were subjected to grain density testing. Oven-dried samples were weighed and then placed in a Beckman air-comparison-type pycnometer to determine their volume (Hironaka, 1966). Only a few grain densities were measured on samples from each. site. However, each major sediment type from each site was tested, and the results were extrapolated to other samples of the same type. 


\section{Compressibility}

Several short unsplit samples were obtained at most of the sites. About half of these were taken from the small metal sleeve which is inserted into the plastic core liner immediately above the core retainers. The material from the sleeve appears to be less disturbed than that of the remainder of the core. The other half of the unsplit samples taken were so-called zero sections. Occasionally drilling for nine meters produced more than nine meters of sample, possibly as a result of sample expansion during retrieval. The extra material is labeled the zero section and is somewhat more disturbed than the remainder of the core. However, since high-recovery cores tend to be less disturbed than low-recovery cores, the disturbance of zero sections is approximately average for the site. In general, of course, all DSDP cores are moderately to highly disturbed in an engineering sense.

The unsplit samples were taken so that consolidation ${ }^{1}$ tests could be performed at a shore laboratory (NCEL). In all, eight of these tests were performed on samples from five sites $(183,184,185,188,190)$. The procedures were as follows. Cylindrical samples $5.91 \mathrm{~cm}$ in diameter and $1.99 \mathrm{~cm}$ in height were cut from the unsplit sample sections. These were inserted into a rigid ring system so that no lateral sample deformation could occur. Porous stones were placed on the sample-free surfaces and the sample-stonering system was submerged in seawater. The sample was then loaded axially and the reduction in sample height measured. Loading was achieved with a Karol-Warner air pressure loading frame without back pressure. Loading followed the usual pattern; an initial load was applied for about 24 hours. The load was then progressively doubled until the equipment limit (about $25 \mathrm{~kg} / \mathrm{cm}^{2}$ ) was reached. The sample was allowed to compress under each load for about 24 hours. After the peak load was reached, the sample was unloaded, generally in two large steps, so that the swelling potential could be determined.

Good discussions of the theoretical implications and practical applications of consolidation testing are provided by Terzaghi (1943) and Taylor (1948).

\section{Triaxial Shear Strength}

NCEL has developed techniques for performing consolidated-unchained triaxial shear tests with pore pressure measurements on sea floor sediments. The usual procedures are followed (Bishop and Henkel, 1962) with modification to allow seawater to be used as a pore fluid. The tests are run under back pressure (about $3.5 \mathrm{~kg} / \mathrm{cm}^{2}$ ) developed with a mercury pot system.

\section{RESULTS AND ANALYSIS}

\section{Introduction}

One of the primary objectives of foundation engineers is to be able to predict whether a proposed foundation or anchoring system will perform satisfactorily during the

\footnotetext{
${ }^{1}$ The term "consolidation" will be used in this report to refer to the compression of sediments under increasing pressures. This is approximately analogous to the geologic term, "compaction."
}

operational life of the structure it supports. "Satisfactory" performance generally implies that the structure does not move more than a predetermined amount as a result of motions in the underlying soil. It is desirable then to be able to predict these motions so that the adequacy of the proposed foundation design can be evaluated. To do this rigorously it would be necessary to determine a general stress-strain-time function for every element of soil affected by the structure. This is currently impossible even on land, although great progress is being made as a result of the development of the finite element method on analysis. On the sea floor, the state of the art is much more primitive because of the difficulty involved in measuring the sediment properties. Here it is usually adequate to be able to predict whether the soil will rupture completely under the structural loading or whether an extremely large amount of sediment compression will occur. To predict these events it is necessary to know the sediment shear strength (shear stress at which rupture occurs) and the sediment compressibility (change in volume which results from a change in normal stress). Even these parameters are quite complex in that they are interrelated and both very dependent upon time. During Leg 19 only two sediment engineering properties were investigated in detail: the short term (undrained) shear strength and the intermediate (drained but without secondary effects) compressibility.

\section{Vane Shear Strength}

\section{BACKGROUND}

Hvorslev (1949) suggested a number of corer design parameters which would be expected to lead to good quality (in an engineering sense) sediment samples and which have generally been accepted by the engineering profession. As an example of one of these parameters, Hvorslev suggested that the corer length should not exceed its inside diameter by more than 20 . The Deep Sea Drilling Project length to diameter ratio is about 140 . The other parameters of Hvorslev are similarly violated and drilling introduces even more disturbance. Therefore, the Deep Sea Drilling Project cores are highly disturbed in an engineering sense. Engineering property measurements are practically meaningless unless this disturbance is considered.

In order to compensate for disturbance it is necessary to develop a means of measuring it quantitatively. A common procedure for doing this is to utilize the residual stresses retained by a sediment after sampling. In situ, the sediments are under a state of compressive stress. Most of this stress is attributable to water pressure, $u$, and may be substracted from the total stress, $\sigma$, to yield what is referred to in soil mechanics as the effective stress, $\bar{\sigma}$.

$$
\bar{\sigma}=\sigma-u
$$

It has been shown that soil response is almost always determined by the effective rather than the total stress. For an element of sediment in situ the vertical effective stress, $\bar{\sigma}_{v o}$, is simply equal to the cumulative buoyant weight of sediment overlying it. The in situ horizontal effective stress, $\bar{\sigma}_{h o}$, is usually less than the vertical effective stress, often by a factor of about 50 percent. As a result, it may be said 
that sediment in situ is under a state of anisotropic (stresses vary with direction), compressive, effective stress. When a sample is taken, there is a tendency for the sample to expand as a result of the removal of stresses. However, in order for any significant amount of expansion to occur, it is necessary for additional fluid to be drawn into the sediment pores. This occurrence will be prevented if the sediment is fine grained and is handled very carefully. Menisci will form in the pores at the sediment surface and prevent fluid intrusion and volume change. However, the residual tendency toward expansion will be reflected in the development of negative gage pressures in the pore water. Referring to Equation 1, it may be seen that a state of zero total stress, $\sigma$, and negative pore water pressure, $u$, produces a positive (compressive) effective stress, $\bar{\sigma}$. Since water cannot maintain shear stresses, the state of stress in the sample is necessarily isotropic (i.e., equal in all directions). In general, therefore, sampling causes a transformation in the state of effective stress within the sediment from one of anisotropic compression to one of isotropic compression. If nothing else occurs in the way of disturbance, the situation is referred to as "perfect sampling." It is possible to approach perfect sampling in a semitheoretical fashion and arrive at the following equation for the residual pore water pressure, $u_{p s}$, which would develop if perfect sampling could be accomplished (Ladd and Lambe, 1963): :

$$
u_{p s}=-\bar{\sigma}_{v o}\left[K o+A_{u}\left(1-K_{o}\right)\right]
$$

where

$$
\begin{aligned}
K_{o}= & \text { Coefficient of lateral earth pressure at rest } \\
& \left(\bar{\sigma}_{h o} / \bar{\sigma}_{v o}\right) \\
A_{u}= & \text { "perfect sampling" pore pressure parameter. }
\end{aligned}
$$

Both $A_{u}$ and $K_{o}$ are related to sediment type and vary from about -0.1 to +0.3 and 0.4 to 0.7 respectively (Ladd and Lambe, 1963). Typical values for average cohesive soils are about +0.1 for $A_{u}$ and 0.5 for $K_{o}$. Inserting these values into Equation 2 yields

$$
u_{p s}=-0.55 \bar{\sigma}_{\nu o}
$$

This relation indicates approximately what pore pressures would develop under perfect sampling conditions. Of course, perfection is never achieved and all samples are somewhat disturbed. Disturbance causes a reorientation of grains, breaking of interparticle bonds, and an overall decrease in the tendency of a sample to expand. The resulting residual pore water pressure, $U_{r}$, is, therefore, less negative than $u_{p s}$. It has been suggested by Ladd and Lambe (1963) and others that the ratio ur/ups is a good measure of the amount of disturbance to which the sample has been subjected. This hypothesis was tested by Lee (in press) on several terrigenous seafloor soils and it was found that the ratio of measured in situ to laboratory vane shear strengths could be correlated relatively well with $u_{r} / u_{p s}$.

\section{RESULTS}

About 700 measurements of vane shear strength were made on shipboard during Leg 19. In addition, about 60 measurements of residual negative pore pressure were made at locations of vane tests. The sediments which appeared to be less disturbed were vane shear tested. The residual pore pressure tests were performed on the highest quality samples available for each depth range.

The measured laboratory vane shear strengths, $S_{L}$, are plotted versus depth in Figures 1 through 10 . The measured residual pore pressures are given on the plots adjacent to the appropriate shear strength measurements.

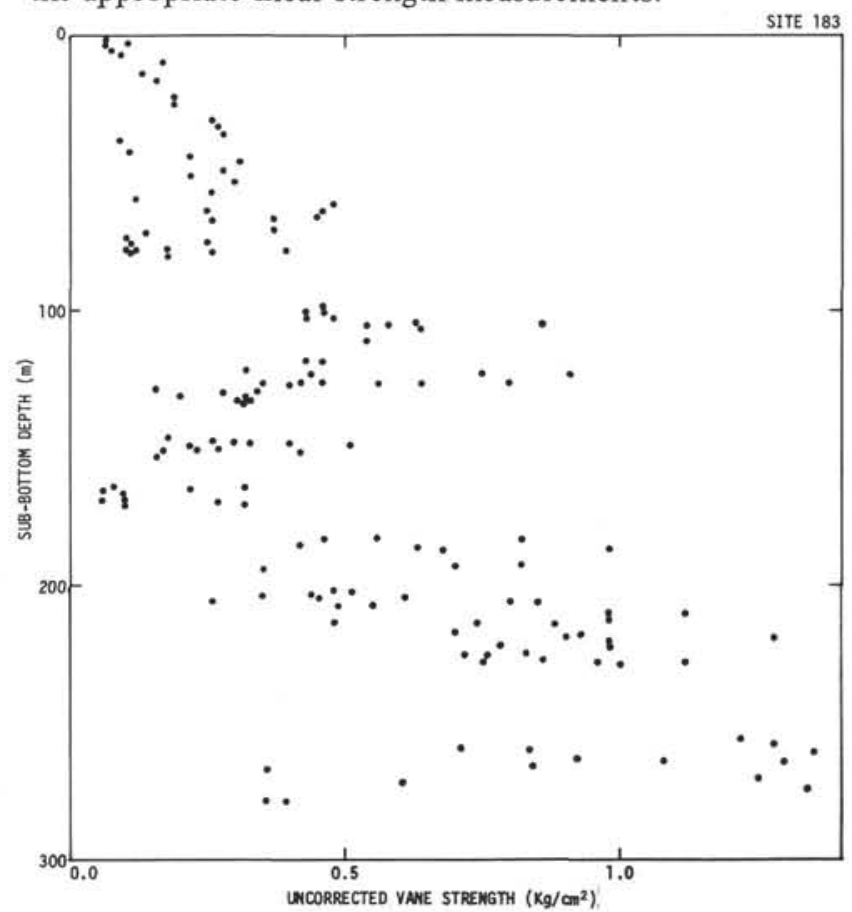

Figure 1. Uncorrected, measured vane shear strength versus subbottom depth, Site 183.

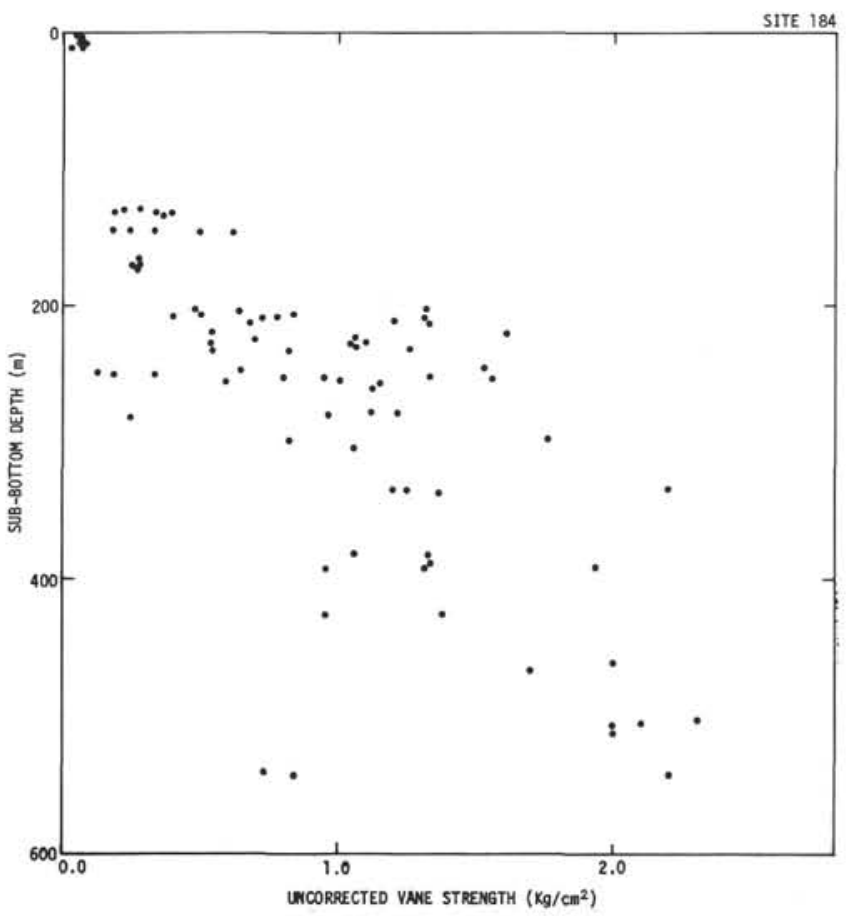

Figure 2. Uncorrected, measured vane shear strength versus subbottom depth, Site 184. 


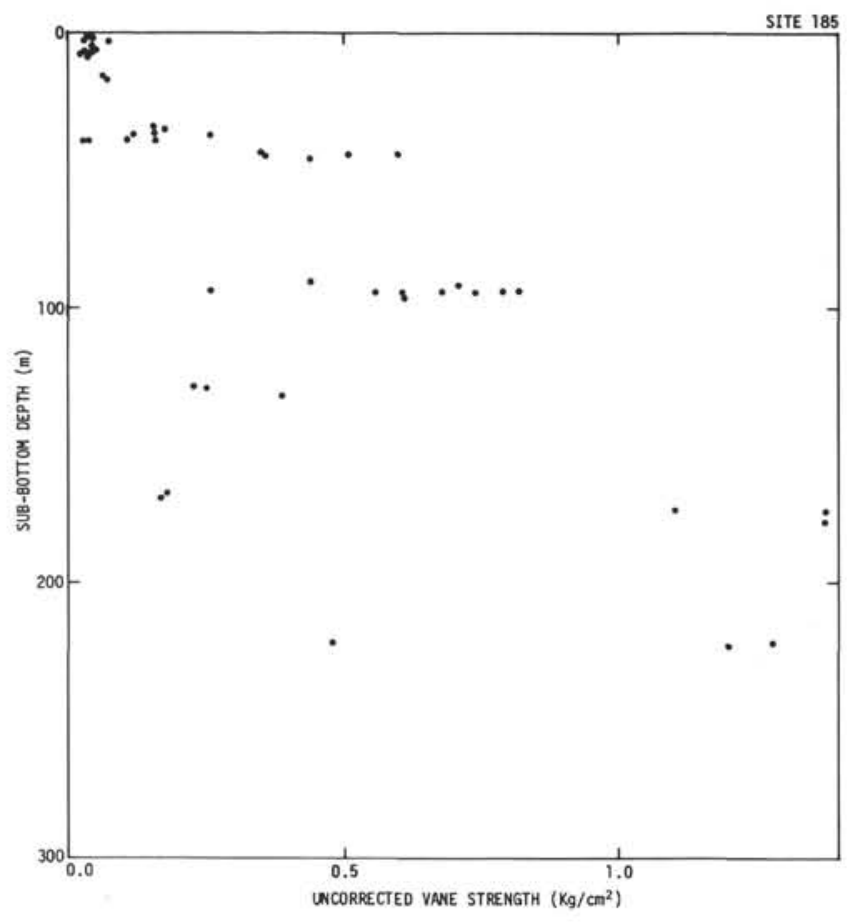

Figure 3. Uncorrected, measured vane shear strength versus subbottom depth, Site 185.

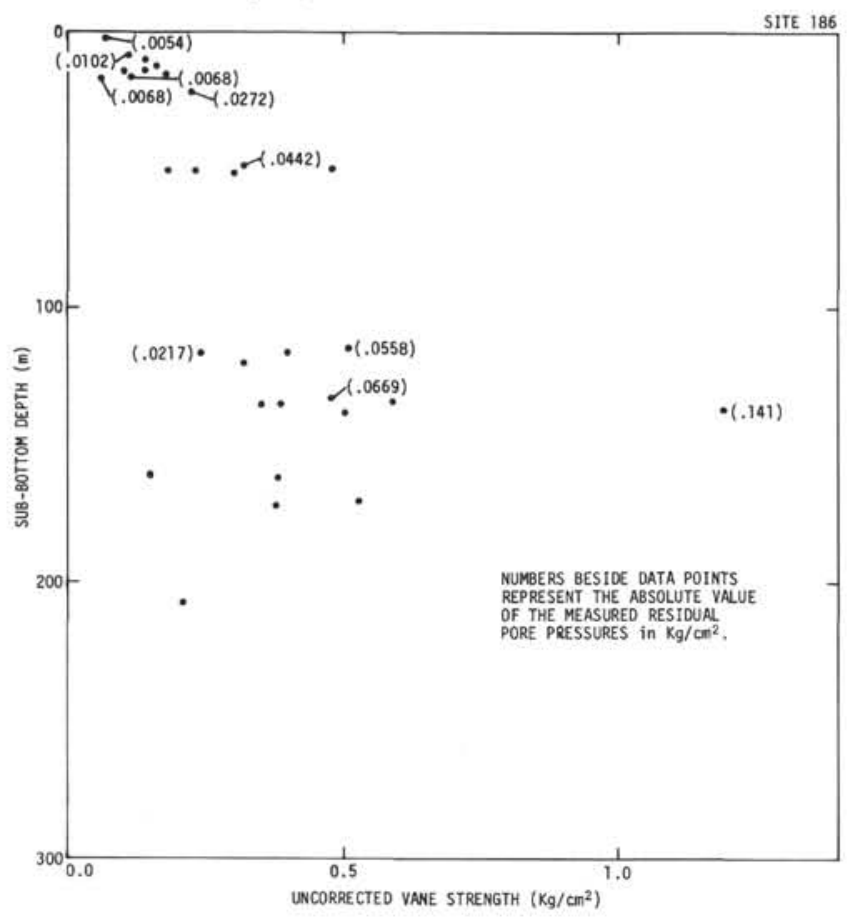

Figure 4. Uncorrected, measured vane shear strength versus subbottom depth, Site 186.

A number of conclusions may be drawn from these curves:

1) Strength usually increases with depth.

2) At about the same depth, higher strengths correspond to more negative residual pore pressures.

3) Uncorrected strength varies strongly with sediment type. For example, samples from the highly diatomaceous

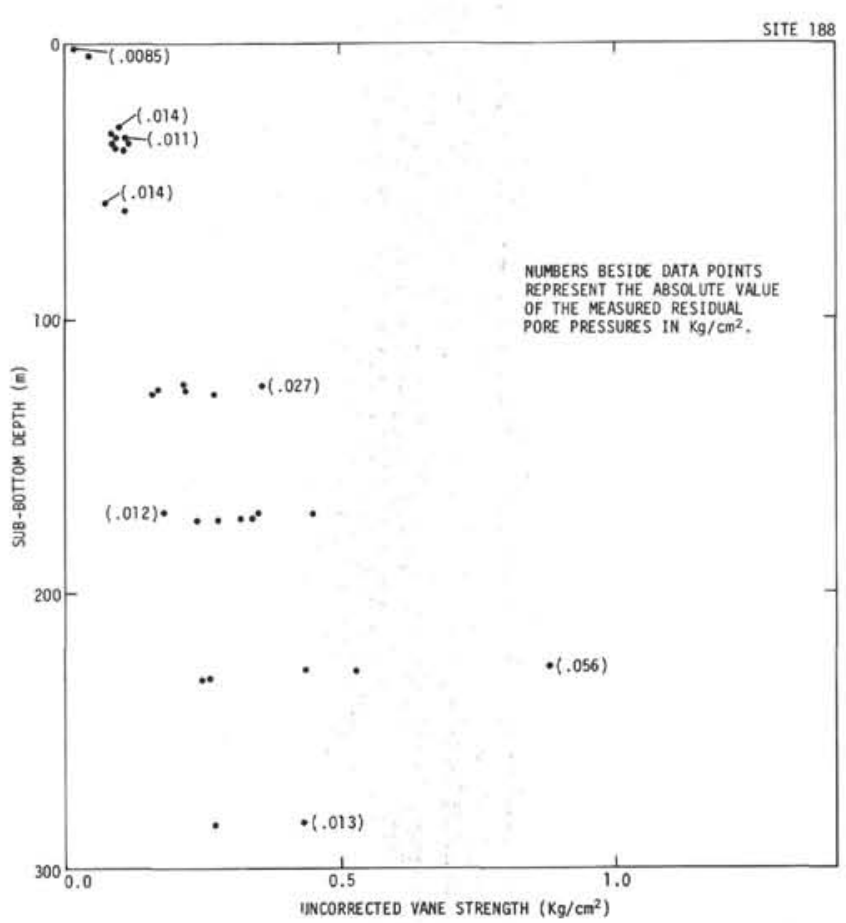

Figure 5. Uncorrected, measured vane shear strength versus subbottom depth, Site 188.

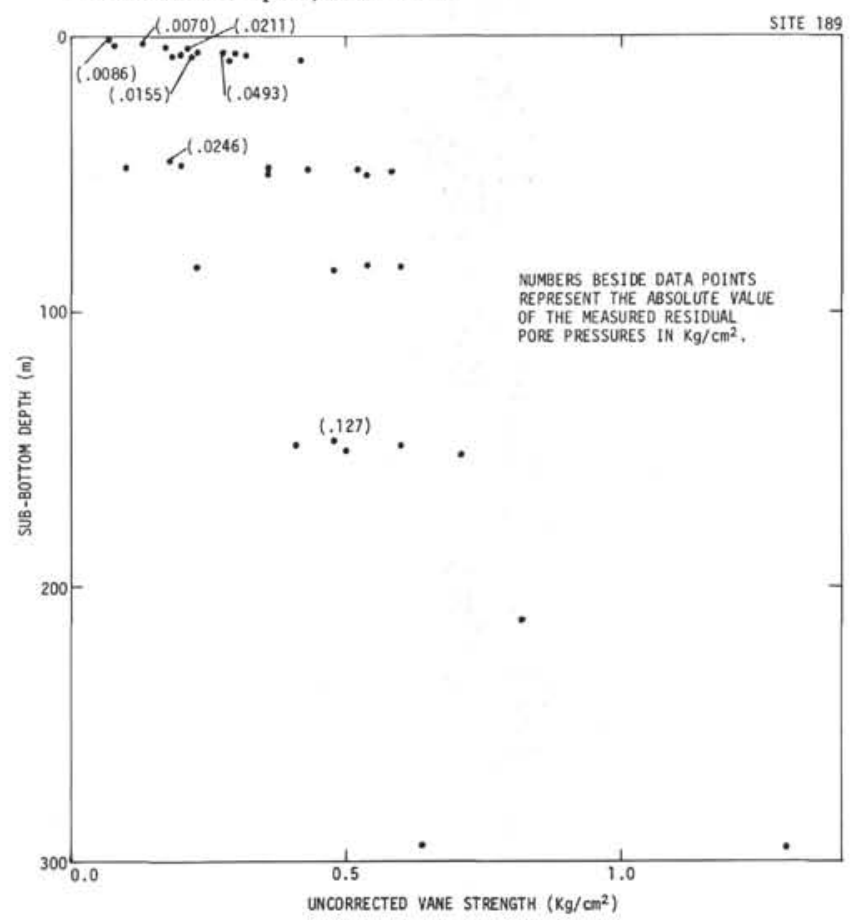

Figure 6. Uncorrected, measured vane shear strength versus subbottom depth, Site 189.

Site 188 are much weaker than those from the more clayey Site 189. Residual pore pressure varies similarly with sediment type.

4) There is a great deal of scatter in the data.

The data of Figures 1 through 10 are somewhat valuable from a qualitative point of view. However, there is no reason to believe that any of the data accurately represent 


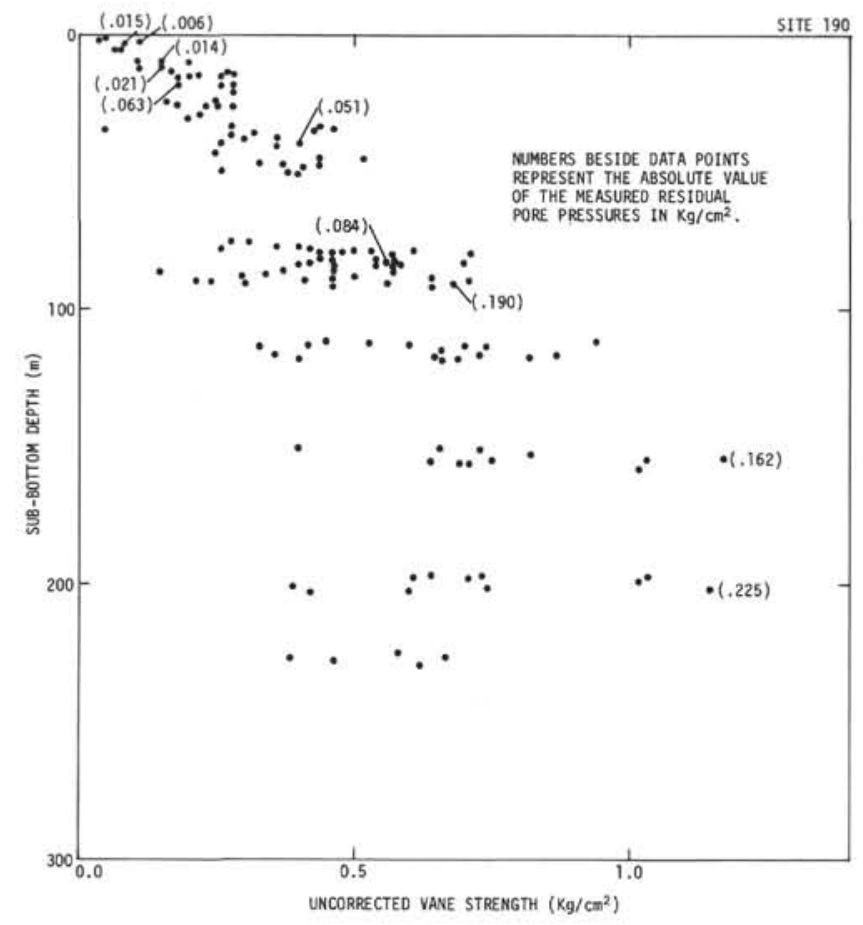

Figure 7. Uncorrected, measured vane shear strength versus subbottom depth, Site 190.

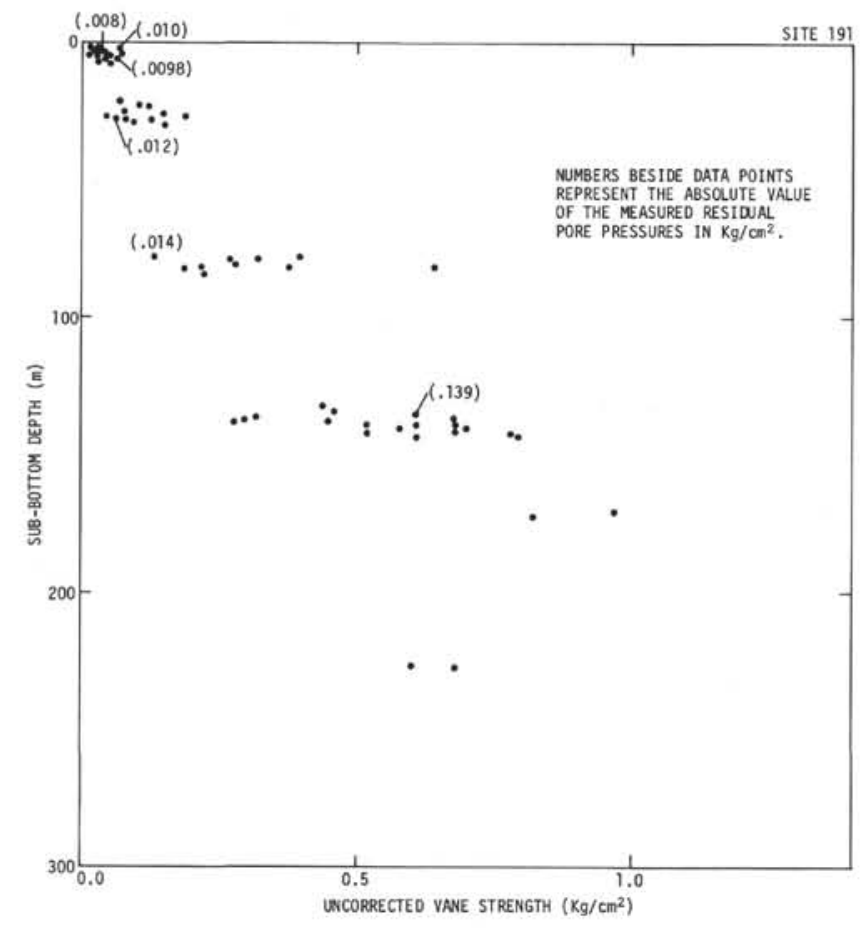

Figure 8. Uncorrected, measured vane shear strength versus subbottom depth, Site 191.

in situ behavior. In order to deduce in situ characteristics, it is necessary to quantitatively utilize the residual pore pressure measurements. This was done by first calculating the in situ vertical effective stress, $\bar{\sigma}_{v o}$, for each sediment depth at which a pore pressure test was run. The shore laboratory densities were used in these calculations

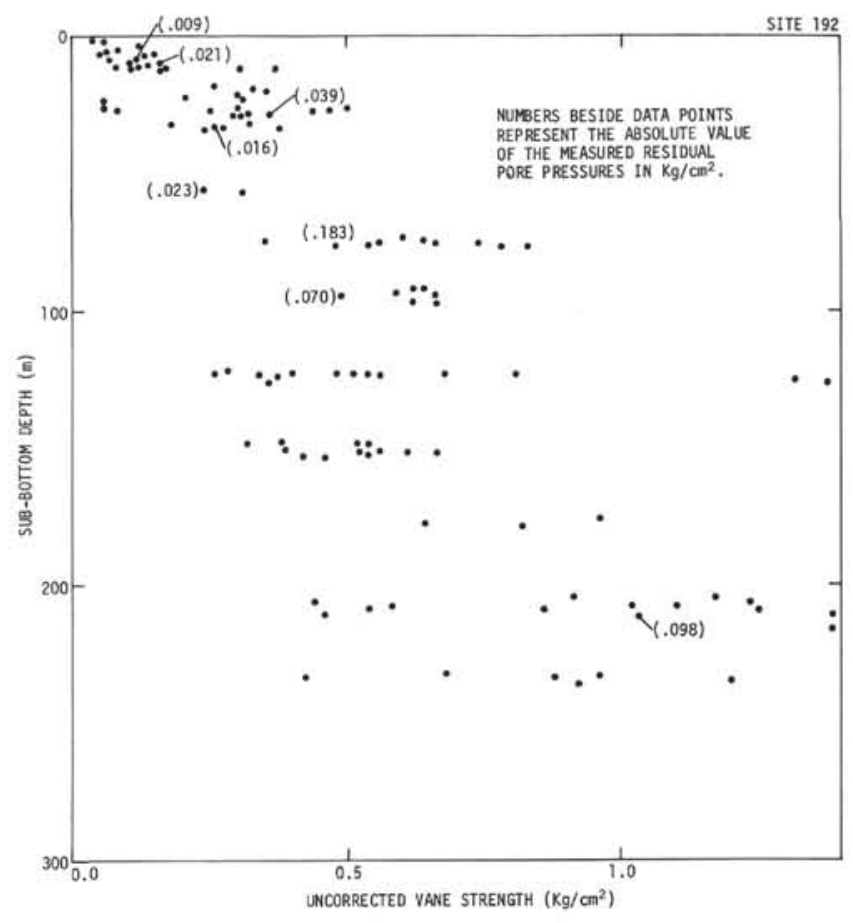

Figure 9. Uncorrected, measured vane shear strength versus subbottom depth, Site 192.

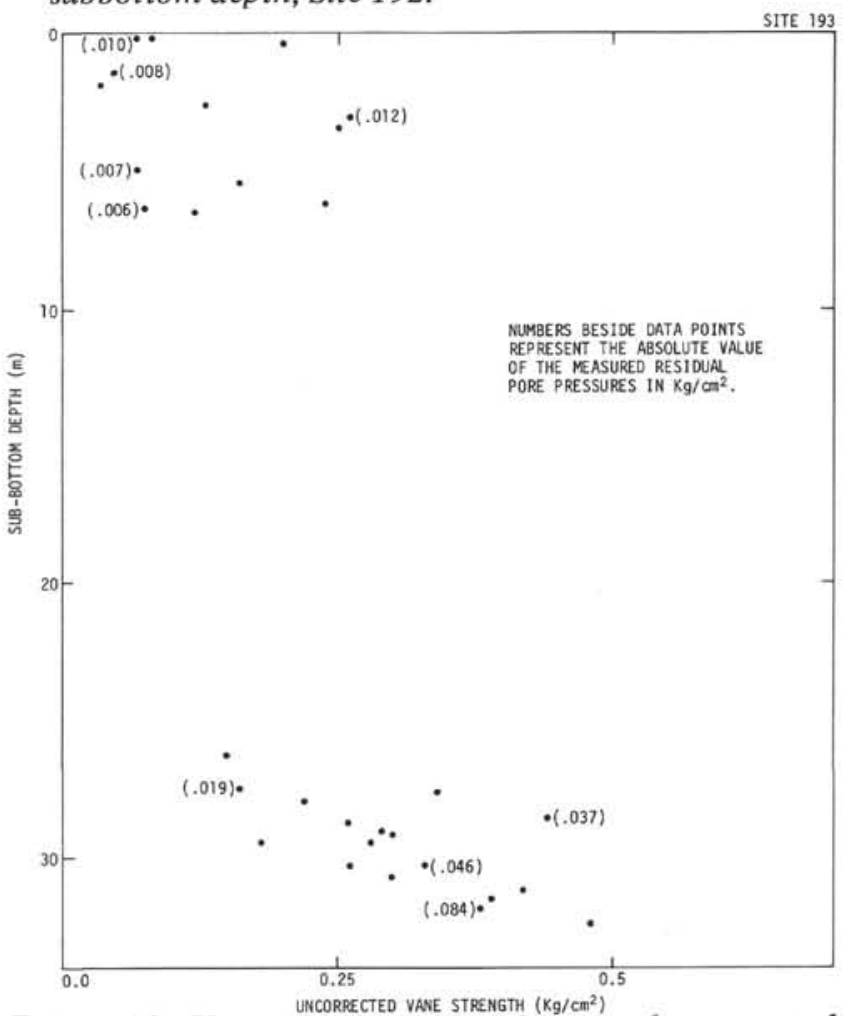

Figure 10. Uncorrected, measured vane shear strength versus subbottom depth, Site 193.

although the GRAPE densities would have yielded comparable values. These stresses were multiplied by -0.55 to obtain an estimate of the residual pore pressure which would result from perfect sampling, $u_{p s}$. The measured residual pore pressures, $u_{r}$, were divided by the se values to obtain ratios, $u_{r} / u_{p s}$, which are measures of disturbance. 
The next step was to determine how these pore pressure ratios would relate to the ratios of laboratory to in situ strength. Ladd and Lambe (1963) provide the series of curves shown in Figure 11. In their original report the axes were labeled somewhat differently and the data were obtained in an entirely different manner. However, Ladd and Lambe (1963) suggest that the data be used in basically the same fashion as given by Figure 11, i.e., as a plot of strength ratio versus pore pressure ratio.

One problem immediately apparent from Figure 11 is that different soils produce different curves on a plot such as this. In the earlier NCEL study (Lee, in press) it was found that terrigenous sediments from the Santa Barbara Channel area followed the Wealt clay curve relatively well. However, there is no reason to believe that Bering Sea and North Pacific sediments will do likewise.

In order to approach this problem, one of the commonly accepted concepts of soil mechanics was relied upon. In a normally consolidated soil (one in which the in situ vertical effective stress, $\bar{\sigma}_{v o}$, has never exceeded its present value), the in situ strength, $S_{f}$, increases linearly with $\bar{\sigma}_{v o}$. That is, the ratio, $S_{f} / \sigma_{v o}$, is a constant.

It was observed that the shapes of the curves in Figure 11 were all approximately the same. To simplify matters, four characteristic curves, having the same shape as the actually measured curves and spanning the complete range of values, were constructed and are shown in Figure 12.

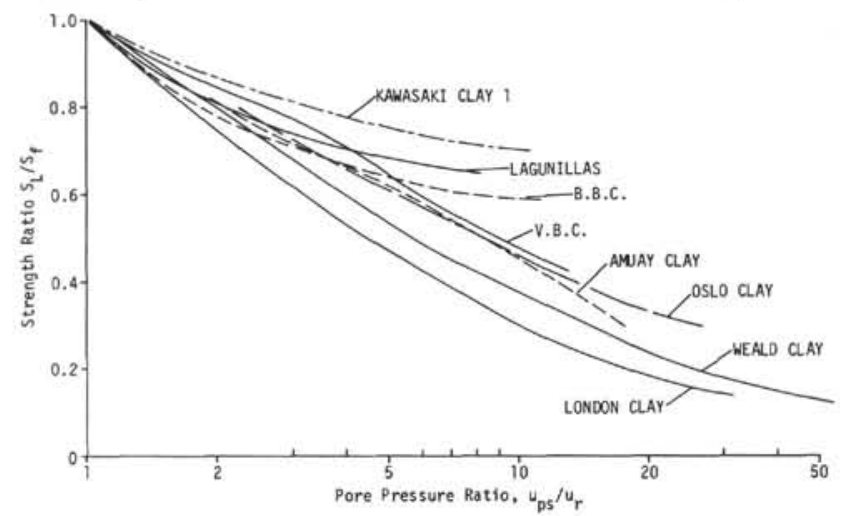

Figure 11. Proposed plot of strength ratio versus pore pressure ratio-based on previous tests - after Ladd and Lambe, 1963.

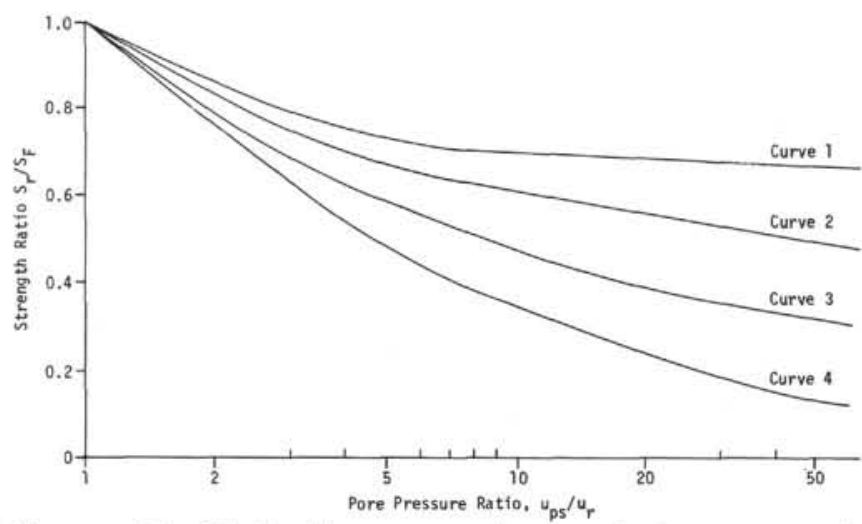

Figure 12. Idealized curves developed to represent influence of pore pressure changes on strength. Curve 3 is recommended for Leg 19.
Given these curves and a set of $S_{L}, u_{r}$, and $u_{p s}$ data, it was possible to calculate four values of in situ strength, $S_{f}$. These values of $S_{f}$ were in turn divided by the appropriate $\bar{\sigma}_{v o}$ to yield four values of the ratio, $S_{f} / \bar{\sigma}_{v o}$, for each set of measured values of $S_{L}$ and $u_{r}$. These data were then analyzed statistically. The variances of the logarithms of each set of $S_{f} / \bar{\sigma}_{v o}$ data (below a sediment depth of about $40 \mathrm{~m}$ ) for each site-Figure 12 curve combination were calculated. The logarithms were used to eliminate pure scaling effects. Data above about 40 meters were not considered in this particular analysis because there is often considerably more variation in $S_{f} / \bar{\sigma}_{v o}$ in this range. The variances were then averaged over the sites to yield four average variances for each of the curves in Figure 12. As a result, curve 3 was found to yield the lowest variance with curve 2, second; curve 4, third; and curve 1, fourth. Curve 3 , therefore, yields values of $S_{f} / \bar{\sigma}_{v o}$ which most nearly satisfy the criterion that $S_{f} / \sigma_{v o}$ should be constant with depth. It is recommended therefore that curve 3 of Figure 12 be used to correct the vane shear strengths measured during Leg 19. A further justification for doing this will be given below in the discussion of the one triaxial test performed.

The estimated in situ vane shear strengths (based on curve 3) for all the points at which residual pore pressure tests were performed are plotted versus depth in Figure 13.

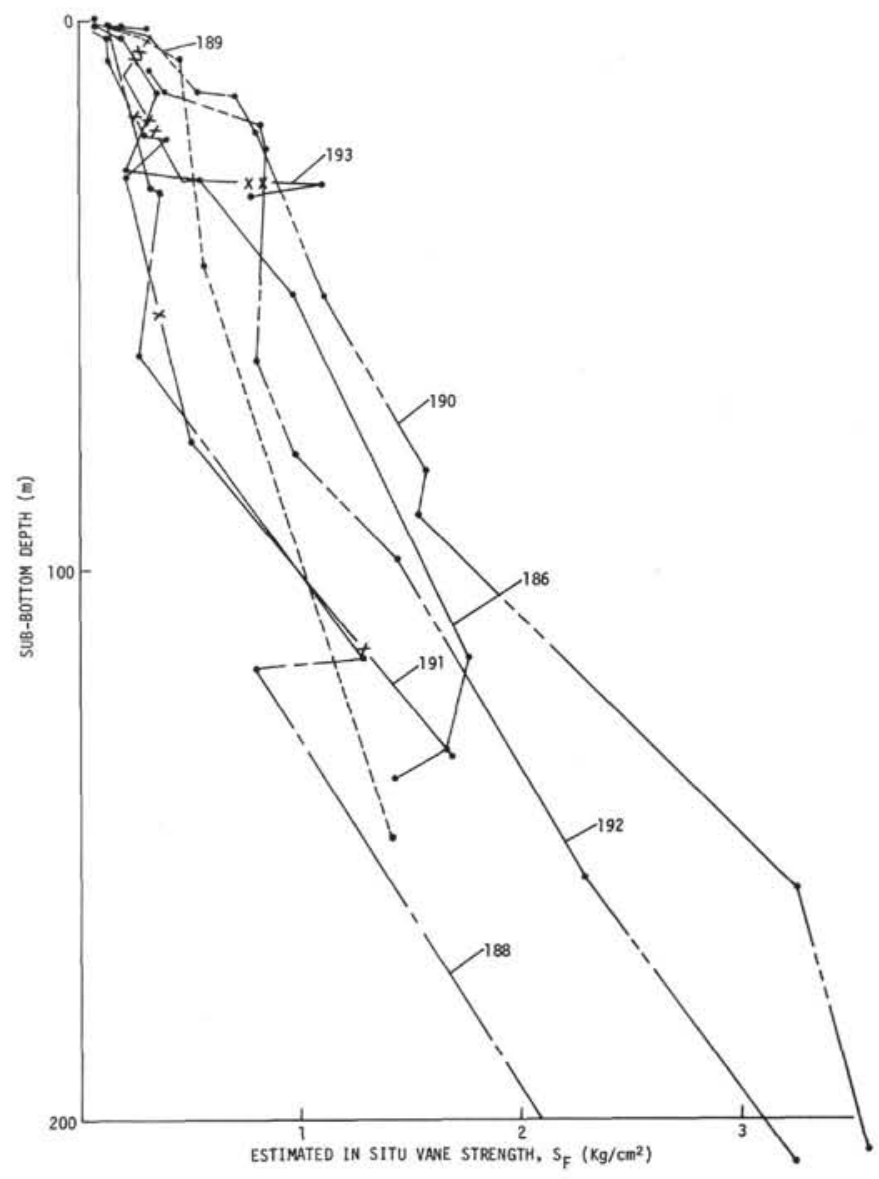

Figure 13. Estimated in situ vane strength versus depthLeg 19 (based on Curve 3, Figure 12). 
Several important points are apparent from these curves:

1) The estimated in situ strength values are much higher (by a factor of 2 to 3 or more) than the measured laboratory strengths (Figures 1-10).

2) The data scatter among the corrected strength values for each site is much less than among the laboratory values. This would appear to indicate that much of the variation in measured values is a result of disturbance rather than actual changes in in situ character.

3) There is not a great deal of variation in estimated in situ strength among the sites themselves for any given sediment depth. Some of the variation that does exist may be a result of errors in the correction technique. It would be possible to construct an average curve through the data for use in design which would be correct within about plus or minus 50 percent.

4) There are three basic types of shear strength-depth plots illustrated. At Sites 186, 188, and 191, the strength increases consistently with depth from a value of near zero at the surface. At 189 and 192, the strength increases very rapidly over the first 10 to 20 meters, passes through an almost uniform zone to 50 to 60 meters, and then begins to increase at about the same rate as the strength at Sites 186, 188, and 191. At Site 190 the strength increases rapidly for the first 20 meters. There is then a change in slope with the strength below that point increasing at about the same rate as at the greater depths of the other sites. These variations could be a result of lithologic changes or errors. However, the possibility that there could be two components of strength also exists. One component would be strictly frictional (increasing linearly with normal stress, $\bar{\sigma}_{v o}$ ) and the other component would be nonfrictional or cohesive (independent of $\bar{\sigma}_{y o}$ ). Sites 186, 188, and 191 would be lacking any significant cohesion component. The cohesive component at Sites 189 and 192 would build up (as a result of aging, chemical alteration, etc.) over the upper 10 to 20 meters and then be destroyed over the next 40 meters (as a result of bond breaking caused by increased overburden). Below 60 meters strength would be primarily frictional. At Site 190 the cohesive strength would build up in the upper 20 meters and not be destroyed below that point (stronger bonds).

It is, of course, difficult to determine how valid these hypotheses are at present. Additional research should show whether they are valid and if so, what environmental and sediment characteristics lead to the different types of bonding.

The data are presented in a somewhat different manner in Figure 14. Here the ratio of estimated in situ strength, $S_{f}$, to vertical effective stress, $\bar{\sigma}_{v o}$, is plotted versus sediment depth. As discussed previously, this ratio was artifically forced to have as little variation as possible below a sediment depth of 40 meters. No constraints were placed on the data above this depth, however. As may be seen, this shallow material always produced a higher $S_{f} / \bar{\sigma}_{y o}$ ratio than the deeper material. The point of divergence is at a sediment depth of about 30 meters, above which, very high values (greater than 1.0) of $S_{f} / \overline{\sigma_{v o}}$ may occur. Below this point, the ratio values are similar to those which have been determined for normally consolidated soils on land $(0.2$ to $0.4)$.

\section{Triaxial Shear Strength}

One consolidated-undrained triaxial test was performed on a sample cut from the zero section of Core 5 from Site 192. The in situ vertical effective stress, $\bar{\sigma}_{\text {vo }}$, would have been about $1.35 \mathrm{~kg} / \mathrm{cm}^{2}$. However, this sample was reconsolidated isotropically (horizontal and vertical stresses equal) to an effective stress level of $5.64 \mathrm{~kg} / \mathrm{cm}^{2}$. Consolidating to stresses much higher than the in situ level is one recommended (Ladd and Lambe, 1963) technique for reducing the effects of disturbance on friction angle and $S_{f} / \bar{\sigma}_{v o}$ ratio. Following consolidation, the sample was failed by increasing the axial load. This was done without drainage (no changes in volume allowed) and the pore water pressures which developed were measured. Using the effective stress relation (Equation 1) it was possible to calculate the effective vertical and horizontal stresses, $\bar{\sigma}_{v}$ and $\bar{\sigma}_{h}$.

One way of expressing these results is in the form of a stress path for the undrained loading portion of the test. A typical stress path is a plot of the quantity,

$$
\frac{\bar{\sigma}_{\nu}+\bar{\sigma}_{h}}{2} \text { versus } \frac{\bar{\sigma}_{\nu}-\bar{\sigma}_{h}}{2} \text { for the loading. }
$$

In mechanics terms, this is a plot of the top points of the Mohr circles representing all of the intermediate stress states. This stress path is shown in Figure 15. A good deal of important information can be drawn from a plot of this sort: however, for the purposes of this report, only a few points need to be noted. First the point of failure should be determined. By the common failure criteria (Max $\bar{\sigma}_{v}-\bar{\sigma}_{n}$ or $\left.\bar{\sigma}_{v} / \bar{\sigma}_{h}\right)$, this is determined to be:

$$
\begin{aligned}
& \frac{\bar{\sigma}_{v}-\bar{\sigma}_{h}}{2}=2.11 \mathrm{~kg} / \mathrm{cm}^{2} \\
& \frac{\bar{\sigma}_{v}+\bar{\sigma}_{h}}{2}=3.63 \mathrm{~kg} / \mathrm{cm}^{2}
\end{aligned}
$$

A line drawn through this point and the origin represents a failure envelope assuming no cohesion intercept. This line makes an angle, $\alpha$, with the horizontal axis which is related to the usual angle of internal friction $\phi$ by the equation:

$$
\begin{gathered}
\operatorname{Sin} \phi=\operatorname{Tan} \alpha \\
\operatorname{Tan} \alpha=\frac{2.11}{3.63}=0.58
\end{gathered}
$$

(Lambe \& Whitman, 1969)

Therefore, $\phi=35.5^{\circ}$.

This is a typical value for a slightly plastic, cohesive soil (Bjerium and Simons, 1960). The sediment was a diatomaceous silty clay.

Another parameter which can be determined from these data is an estimate of the strength to overburden pressure ratio, $S_{f} / \bar{\sigma}_{v o}$. The initial vertical consolidation stress for this test was $5.64 \mathrm{~kg} / \mathrm{cm}^{2}$ and the measured shear strength (assumed equal to $\bar{\sigma}_{v}-\bar{\sigma}_{h} / 2$ ) was $2.11 \mathrm{~kg} / \mathrm{cm}^{2}$. The strength to pressure ratio was then $2.11 / 5.64$, or 0.37 . 


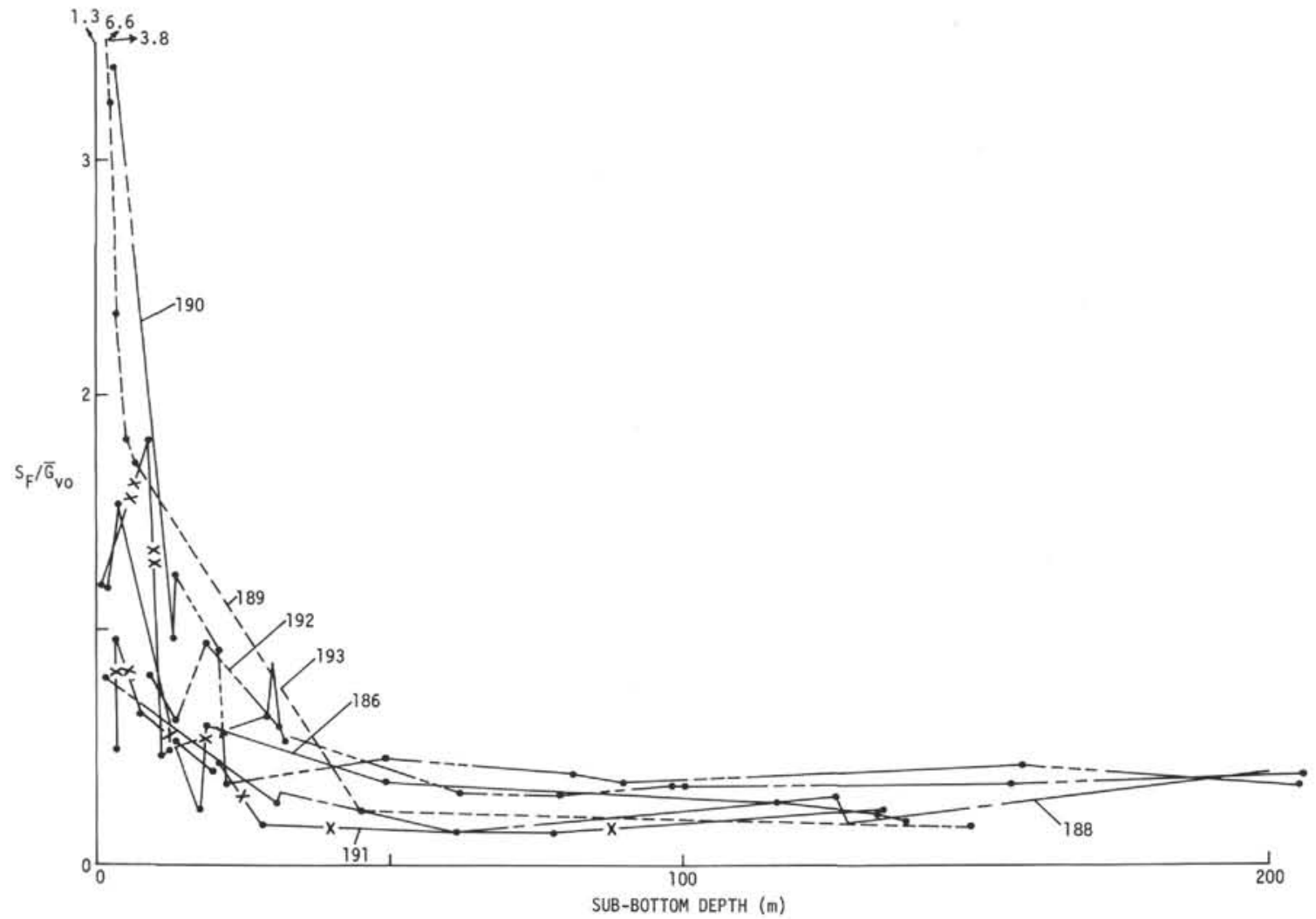

Figure 14. Variation of estimated in situ strength - vertical effective stress ratio $\left(S_{\mathrm{F}} / \mathrm{G}_{\mathrm{vo}}\right)$ with subbottom depth.

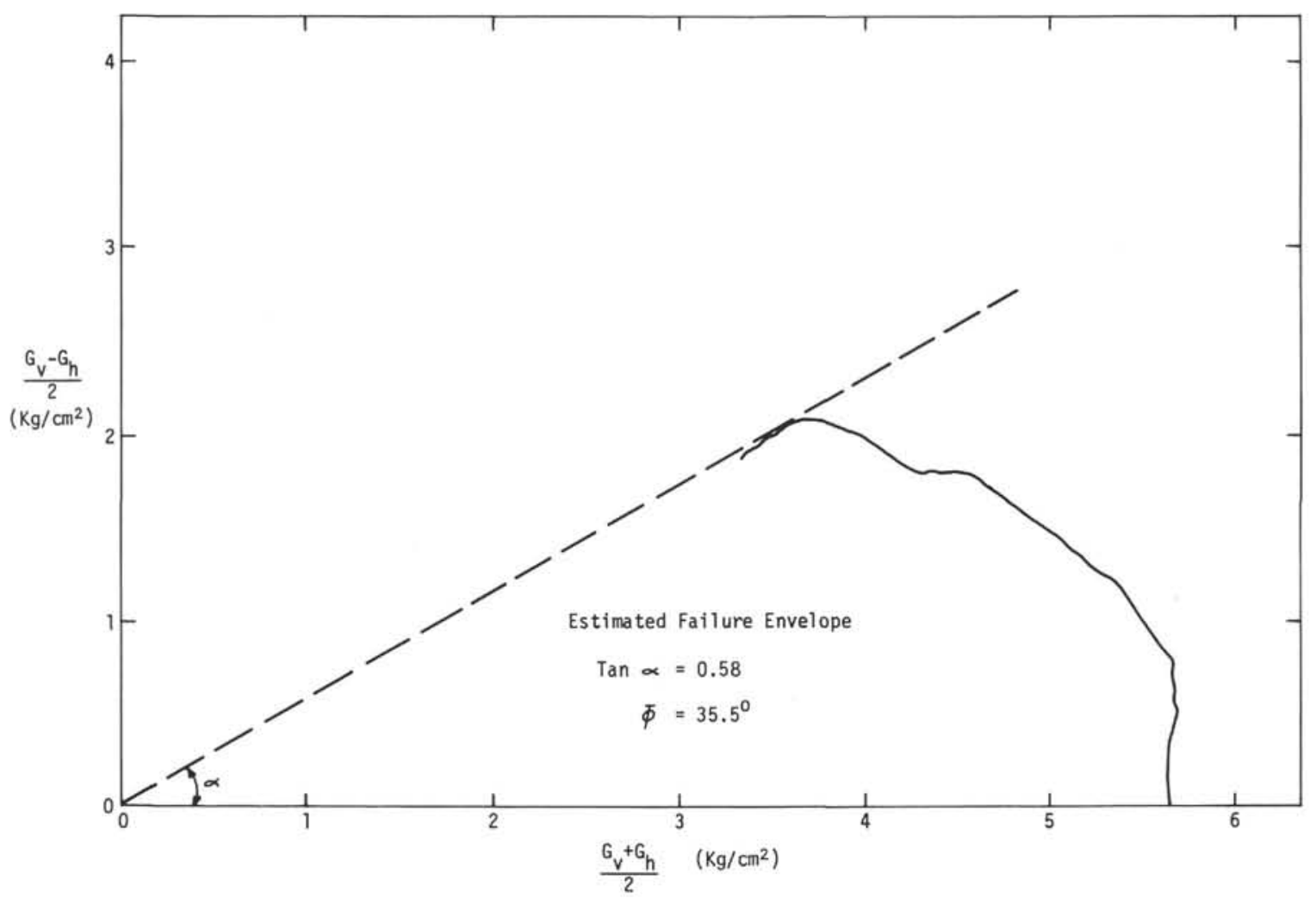

Figure 15. Stress path for consolidated-undrained triaxial test Site 192 - Core 5 - Zero station. 
Consolidating to $5.64 \mathrm{~kg} / \mathrm{cm}^{2}$ approximately simulated a sediment which has that vertical effective stress in situ. At Site 192 this stress would correspond to a depth of 130 meters. The vane shear strength and residual pore pressure were measured on a sample from 156 meters. Using the four curves of Figure 12 to predict in situ strengths, the following values of $S_{f} / \bar{\sigma}_{\nu o}$ were obtained.

$\begin{array}{cc}\text { Curve } & S_{f} / \overline{\sigma_{v}} \\ 1 & 0.17 \\ 2 & 0.22 \\ 3 & 0.34 \\ 4 & 0.69\end{array}$

Once again curve 3 appears to yield the best results with a strength to pressure ratio of 0.34 , versus a measured 0.37 .

\section{Compressibility}

\section{BACKGROUND}

The compressibility of sediments has traditionally been approached in two ways:

1) A sample is taken and compressed rather rapidly (usually 24 hours per load increment). The compressibility for each loading is obtained and generally used to predict how much a structure will settle. Relatively good agreement between predicted and observed results has been obtained.

2) The in situ porosity or void ratio is measured as a function of depth. The change in void ratio with increasing overburden stress is taken as the field compressibility. This value relates to how the sediment compacts as additional material is deposited on the surface.

The difference between these two approaches is clearly the time factor, but it is difficult to determine exactly what influence it may have. Schmertmann (1955) presents data on a number of river bottom deposits which show that the field and laboratory consolidation data are virtually identical if the laboratory data are corrected for disturbance and the sediment is normally consolidated. Leonards and Altschaeffl (1964), however, present data on laboratory consolidation tests run at radically different rates which show that sediment compressibility at low loading rates (still high in a geologic sense) is much lower than at high rates. The authors attribute this effect to the formation of strong interparticle bonds (resulting from the reorientation of water molecules in the vicinity of contact points) during long-term loading. Hamilton (1964), in analyzing the results of tests on samples from the experimental Mohole (Guadalupe Site), developed a conclusion similar to that of Leonards and Altschaeffl. However, he attributed the low rate of field consolidation to the development of chemical cementation in the vicinity of interparticle bonds. Unpublished Naval Civil Engineering Laboratory data indicate an inverse trend-greater field than laboratory compressibility. This can be rationalized in terms of a great deal of long-term (secondary) compression occurring in the field but not occurring in a short-term laboratory test.

The situation is a complex one and it is difficult to determine which factors dominate under which conditions. Sample disturbance and sediment type variation with depth compound the problem.

\section{RESULTS}

During Leg 19, measurements of both field and laboratory compressibility were attempted. Sample densities were calculated using the shore laboratory water contents, grain densities, and the tables provided by Bennett et al. (1971). These were assumed equal to the in situ densities. It is recognized that slight changes in density occur during sampling. However, aside from the slight (1 to $2 \%$ ) amount of change resulting from direct expansion of pore water, it is almost impossible to quantitatively evaluate these changes. In any case, density is perhaps the most reliable physical property which can be obtained from disturbed samples. These densities were converted to void ratios, $e$, which were plotted versus the logarithms of calculated in situ vertical effective stress, $\bar{\sigma}_{v o}$. These field compressibility data are shown in Figures 16 through 25.

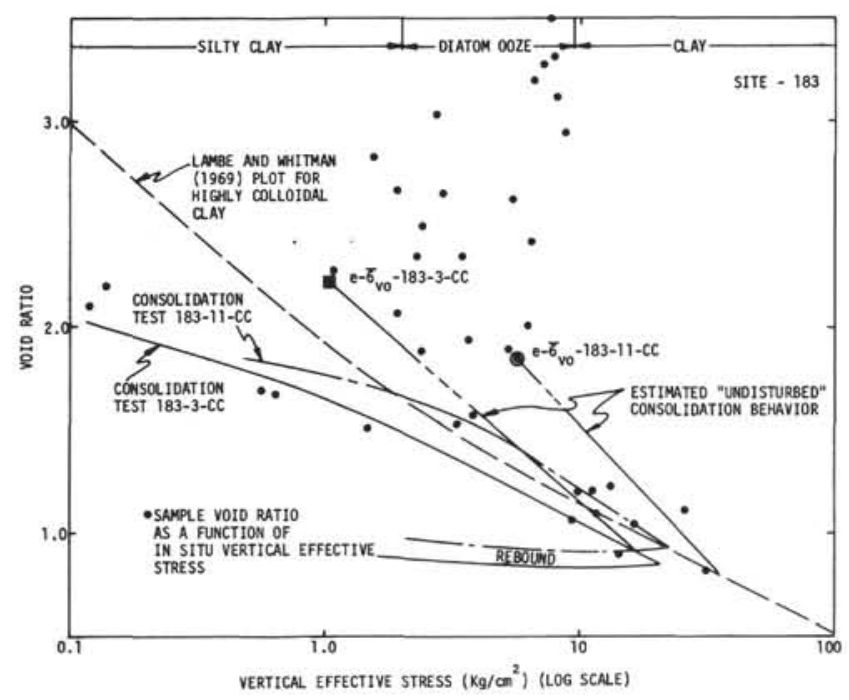

Figure 16. Sediment compression data, Site 183.

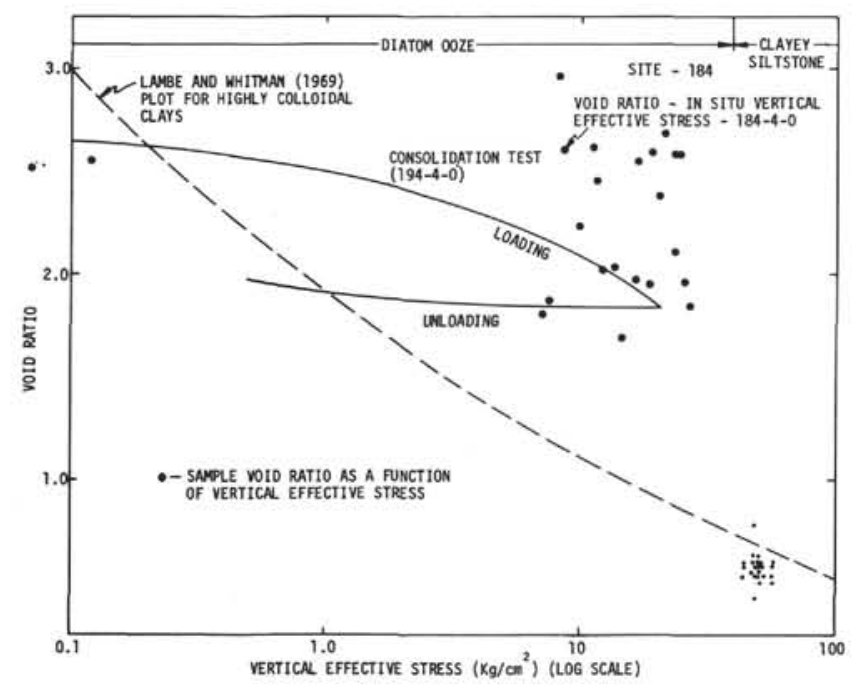

Figure 17. Sediment compression data, Site 184. 


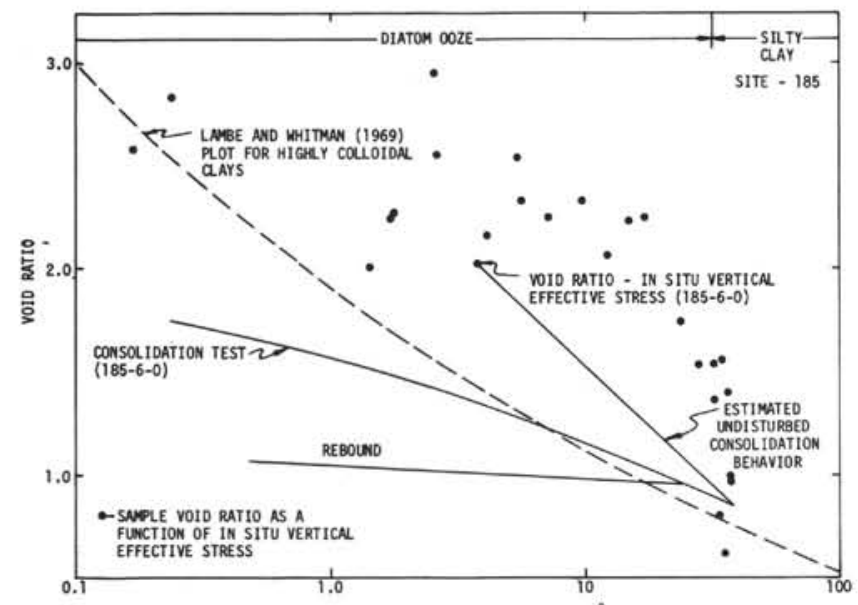

LOG VERTICAL EFFECTIVE STRESS $\left(\mathrm{kg} / \mathrm{cm}^{2}\right)$

Figure 18. Sediment compression data, Site 185.

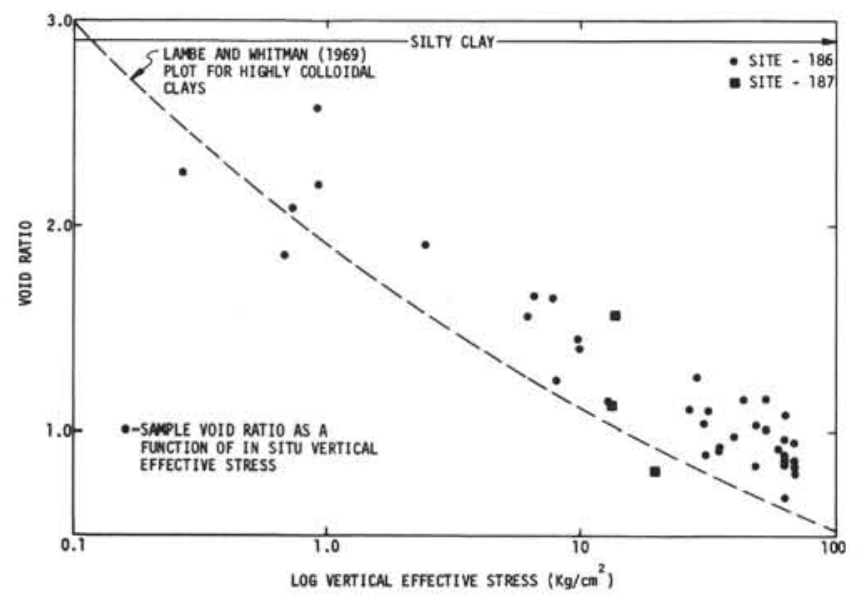

Figure 19. Sediment compression data, Sites 186 and 187.

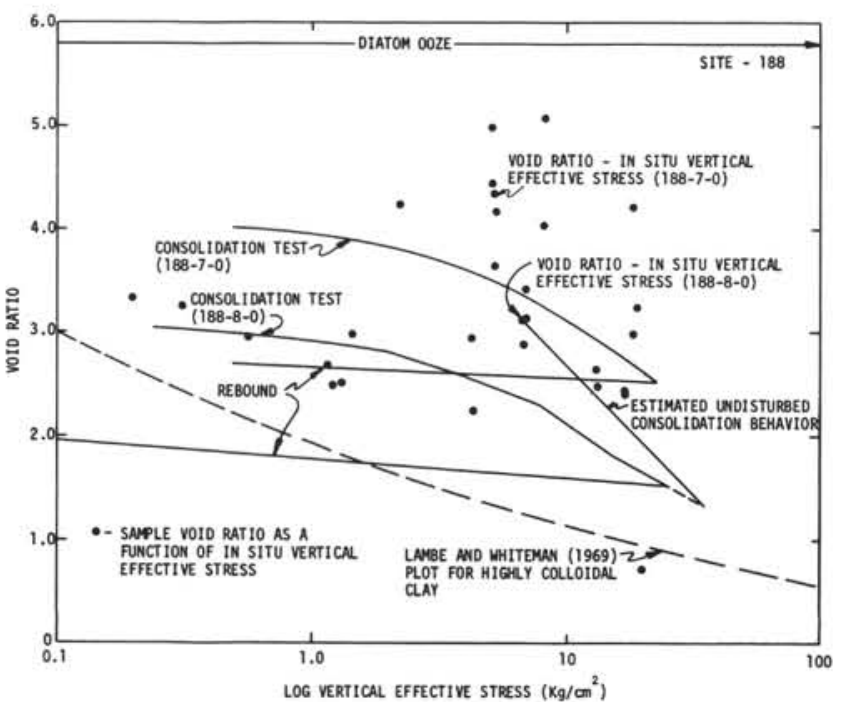

Figure 20. Sediment compression data, Site 188.

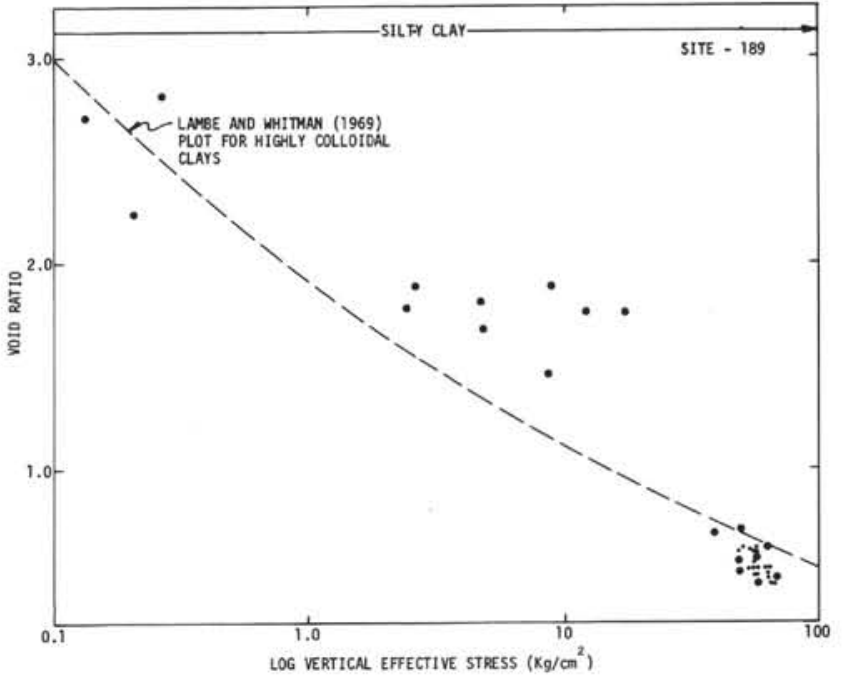

Figure 21. Sediment compression data, Site 189.

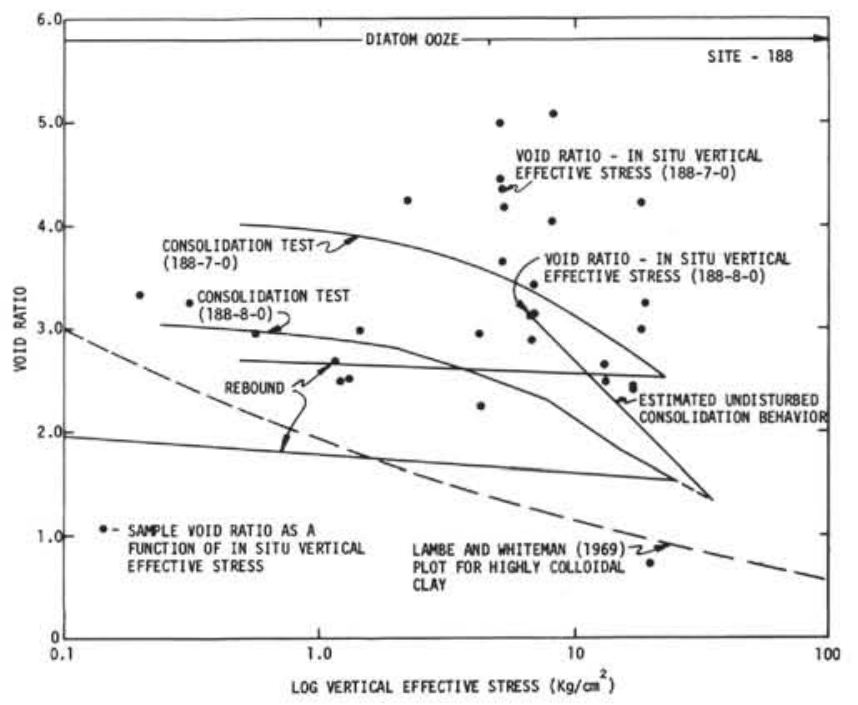

Figure 22. Sediment compression data, Site 190.

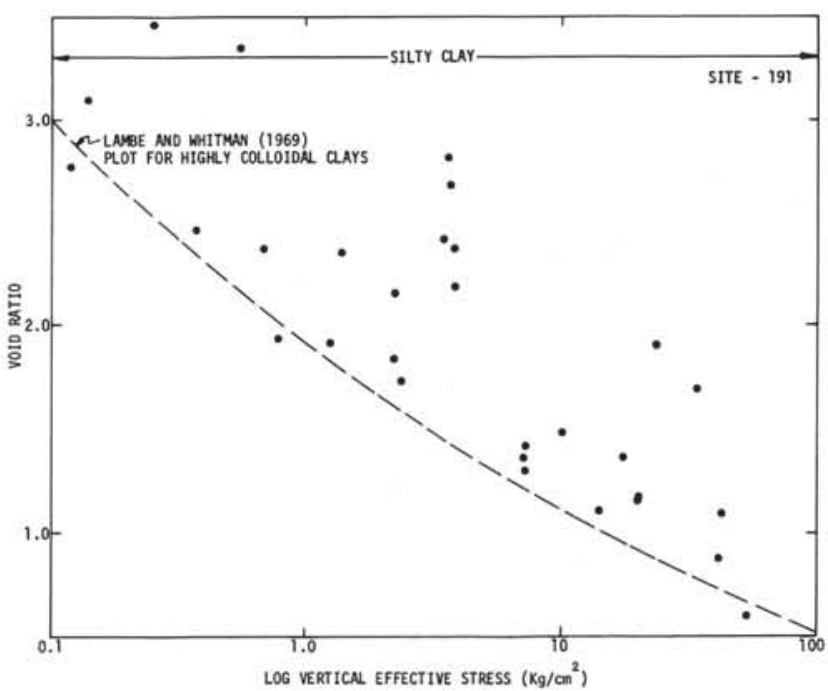

Figure 23. Sediment compression data, Site 191. 


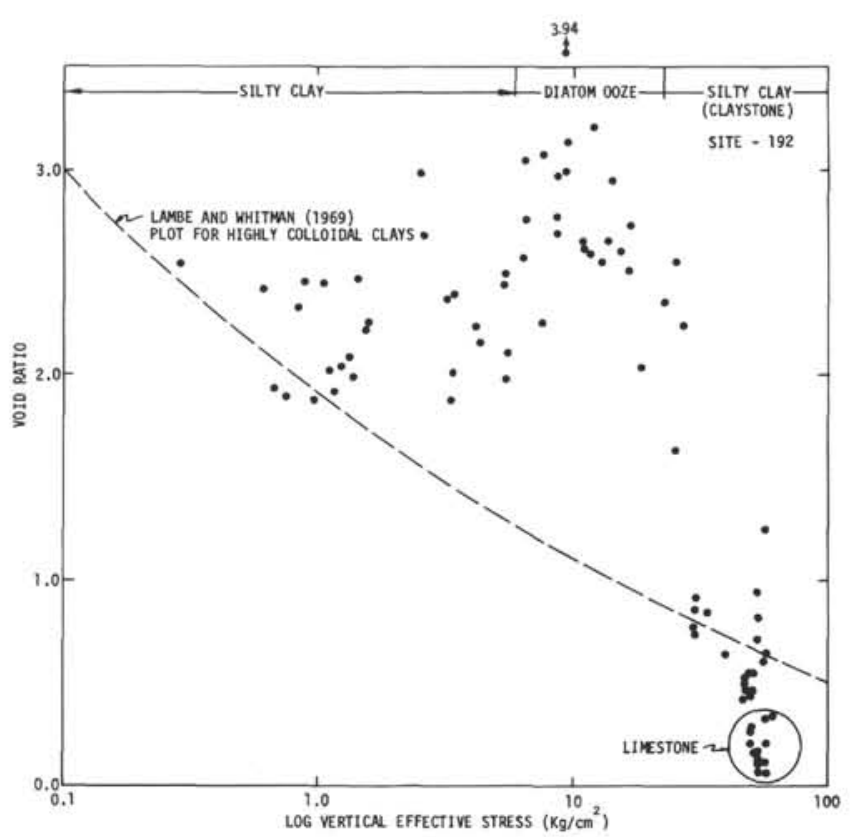

Figure 24. Sediment compression data, Site 192.

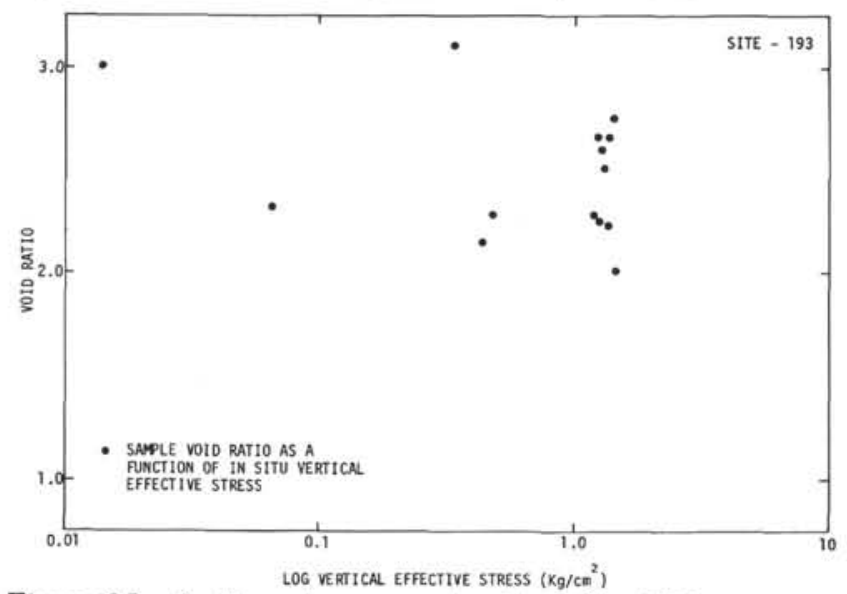

Figure 25. Sediment compression data, Site 193.

Also plotted on these figures are the results of the laboratory consolidation tests. Each test is presented as a loading curve followed by an unloading curve. For each test the point which represents the estimated in situ sample void ratio and vertical effective stress is denoted by a special symbol. Under ideal conditions the loading portions of the consolidation curves would pass through these points. As may be seen, the curves pass well below the points indicating a great deal of disturbance.

A curve taken from Lambe and Whitman (1969) is drawn on each plot. This curve was developed on the basis of a considerable amount of data and is typical of the compression behavior of a highly colloidal clay.

\section{ANALYSIS}

\section{Maximum Past Pressures}

Casagrande (1936) suggested a graphical technique for estimating the maximum past pressure (largest vertical effective stress to which a sediment has ever been subjected), $\bar{\sigma}_{\nu m}$, on the basis of standard consolidation test results. This technique was applied to most of the consolidation test curves to yield the following results:

\begin{tabular}{crccc}
\hline Site & Core & Section & $\begin{array}{c}\text { In-situ Vertical } \\
\text { Effective Stress, } \\
\bar{\sigma}_{\text {vo }}\left(\mathrm{kg} / \mathrm{cm}^{2}\right)\end{array}$ & $\begin{array}{c}\text { Estimated Maximum } \\
\text { Past Pressure, } \\
\bar{\sigma}_{\text {vm }}\left(\mathrm{kg} / \mathrm{cm}^{2}\right)\end{array}$ \\
\hline 183 & 3 & CC & 1.1 & 1.2 \\
183 & 11 & CC & 5.6 & 4.6 \\
184 & 4 & 0 & 8.3 & $?$ \\
185 & 6 & 0 & 3.8 & 3.0 \\
188 & 7 & 0 & 5.1 & $?$ \\
188 & 8 & 0 & 6.9 & 5.6 \\
190 & 7 & CC & 4.1 & 2.5 \\
190 & 9 & CC & 6.0 & 6.0 \\
\hline
\end{tabular}

The graphical constructions are shown on Figures 16 through 25. The Casagrande construction could not be applied to two of the curves representing highly diatomaceous material for reasons which will be given later.

As may be seen, the estimated maximum past pressures do not vary greatly from the current in situ vertical effective stresses. The few differences which do exist can be rationalized in terms of disturbance. It is difficult to apply the Casagrande construction accurately on a curve based on a disturbed sample. In general, therefore, there is no indication that any of the samples tested are anything other than normally consolidated, i.e., that the actual maximum past pressure is different from the current in situ vertical effective stress.

\section{Comparison of Field and Typical Highly Colloidal Clay Data}

The sediments sampled during Leg 19 consisted almost entirely of silty clay, diatom ooze, or a mixture of silty clay and diatom ooze. The subbottom depths over which either diatom ooze or silty clay predominated are delineated in Figures 16 through 25 . As may be seen, there is a clear correlation between field compression data and sediment type. The silty clay data compares favorably with the Lambe and Whitman (1969) curve for a highly colloidal clay. The diatom ooze data deviates significantly (much higher void ratios) from this curve.

\section{Estimation of Undisturbed Consolidation Behavior}

Schmertmann (1955) observed that virtually all samples of the same sediment, ranging from completely remolded to almost undisturbed, consolidate to the same void ratio under the same stress if the stress is high enough to compress the sample to a void ratio less than 42 percent of its initial void ratio. That is to say, all consolidation test curves converge at around $0.42 e_{O}$, where $e_{O}$ is the initial void ratio.

It is generally observed that the void ratio varies approximately linearly with the logarithm of effective stress once the maximum past pressure has been exceeded. The Leg 19 samples appeared to be normally consolidated so these linear variations should begin at the points with coordinates of in situ vertical effective stress, $\bar{\sigma}_{\nu o}$, and in situ (assumed equal to sample) void ratio, $e_{O}$. Using Schmertmann's observation, these lines should intersect the laboratory consolidation curves at $0.42 e_{O}$ and represent an 
estimate of how the sediment would consolidate if it were completely undisturbed. These estimates of undisturbed consolidation behavior are shown in Figures 16 through 25.

Unfortunately, all but one of the consolidation tests were performed on samples of diatom ooze. The one exception (Site 183, Core 3, core catcher sleeve sample) was performed on a silty clay. As may be seen (Figure 16), the estimated undisturbed consolidation curve for this sediment agrees relatively well with the Lambe and Whitman (1969) curve for highly colloidal clay. Since this latter curve was found to agree with the field consolidation data for silty clay, there is some reason to believe that the field data may be estimated using short-term consolidation test results. This might imply that neither the conclusions of Leonards and Altschaeffl (1964) nor Hamilton (1964) regarding cementation and time effects are applicable to the North Pacific and Bering Sea silty clays.

The estimated undisturbed consolidation curves for the diatom oozes are much more difficult to evaluate because the field data on these sediments are extremely scattered. A discussion of the implications of these follows.

\section{Consolidation Behavior of Diatom Oozes}

The diatom oozes which were sampled displayed extremely high void ratios under substantial overburden pressures. Consider, for example, Site 188 where void ratios as high as 5.0 were found at subbottom depths in excess of 150 meters. There are at least two ways in which a material such as this could have been formed: (a) It could have been deposited at a much higher void ratio and then compressed at the rate suggested by the estimated undisturbed consolidation curves of Figures 16 through 25; or (b) it could have been deposited and maintained at about the same void ratio as it has now. This would imply a nearly incompressible material.

To determine which of these processes is most probable, a sample from Core 8 , Site 188 , was suspended in seawater and allowed to resediment over a period of 24 hours. A void ratio of 4.2 was obtained. This sample originally had a void ratio of 3.1 and was taken from a subbottom depth which would produce a vertical effective stress of 6.9 $\mathrm{kg} / \mathrm{cm}^{2}$. Compressing from a void ratio of 4.2 to one of 3.1 implies a volume change of only 20 percent, a very slight amount for a stress increment of this magnitude. It may then be tentatively concluded that diatom oozes have high void rates at large embedment depths because they are almost incompressible and not because they have compressed to that point from much higher void ratios.

There is still the problem that the consolidation test results, especially the estimated undisturbed curves, indicate a relatively great amount of compressibility. One possible explanation for this may be seen by observing the shape of the consolidation curves for several of the tests. For the test on the Site 188 , Core 7 sample and the one test on a Site 184 sample, the consolidation curves never reach a linear portion as would generally be expected. Instead, the slope of the curve increases steadily with the logarithm of effective stress. This could easily be a result of grain crushing which begins to occur at around $5-7 \mathrm{~kg} / \mathrm{cm}^{2}$ and then continues to occur with increasing frequency at higher stress levels. A hypothesis of this nature would allow for the ooze to appear to be very compressible at high stresses while behaving almost incompressibly at low to moderate stress levels. The hypothetical general model of diatom ooze consolidation which results is as follows. The individual diatoms originally deposit themselves relatively closely although the resulting void ratio is high by virtue of the high porosity of each individual grain. As stress increases with increasing overburden, the grains roll and pack slightly more closely. However, since they were relatively closely packed originally, the net compression is small. Finally, the crushing strength of the grains is exceeded at high stress levels and the material begins to behave very compressibly.

This problem of continuing curvature of the consolidation curves at high stress levels made both Casagrande (1936) and Schmertmann (1955) type constructions impossible.

\section{Comparison of Density and Water Content Measurement Techniques}

A variety of different techniques were used to measure densities and water contents. Of these the most accurate (and also most time-consuming) is that involving taking samples on shipboard, carefully sealing, and measuring water content and grain density onshore. These measurements can then be used as a basis for checking the accuracy of the shipboard measurements (GRAPE and syringe). All of the possible comparisons of the shore laboratory density and GRAPE density and shore laboratory water content with shipboard syringe water content are given in Table $1^{2}$. Table 2 presents average values of each quantity measured by each method at each site. Also given are the average absolute differences between shipboard and shore measurements for each site and for the leg as a whole.

As may be seen, the GRAPE densities deviate from the shore densities by about 5 percent on the average while the shipboard syringe water contents differ from the shore laboratory water contents by about 10 percent on the average. Much of the GRAPE density variation was accumulated at Sites 186 and 191, however, both locations at which the samples contained a good deal of gas. For this situation there is a basic difference in the GRAPE method of measurement and the shore laboratory technique: the GRAPE measures the density of the sample which the shore laboratory technique estimates what the density would be if the sample were completely saturated. Obviously, if the gas content is high, the two values differ. Ignoring Sites 186 and 191, the difference between GRAPE and shore laboratory measurements is an easily tolerable 2.7 percent.

Water content is not affected by gas content; therefore, there is no way to reduce the average deviation between syringe and shore laboratory measurements. The 10 percent error introduced by the syringe is probably intolerable for anything other than a rough approximation.

\footnotetext{
${ }^{2}$ Water contents are defined by the engineering convention as weight of water divided by weight of solids.
} 
TABLE 1

Comparison of Density and Water Content Measurements-Individual Values

\begin{tabular}{|c|c|c|c|c|c|c|c|}
\hline Hole & Core & Section & Interval & $\begin{array}{c}\text { Shore Lab. } \\
\text { Density } \\
\text { (g/cc) }\end{array}$ & $\begin{array}{c}\text { GRAPE } \\
\text { Density } \\
(\mathrm{g} / \mathrm{cc})\end{array}$ & $\begin{array}{l}\text { Shore Lab. } \\
\text { Water Content } \\
\text { (\% dry wt.) }\end{array}$ & $\begin{array}{c}\text { Syringe } \\
\text { Water Content } \\
\text { (\% dry wt.) }\end{array}$ \\
\hline \multirow[t]{5}{*}{183} & $\begin{array}{l}4 \\
5 \\
6 \\
6 \\
7 \\
7\end{array}$ & $\begin{array}{l}2 \\
4 \\
2 \\
4 \\
2 \\
4\end{array}$ & $\begin{array}{c}129-132 \\
17-20 \\
133-136 \\
10-13 \\
141-144 \\
135-138\end{array}$ & $\begin{array}{l}1.67 \\
1.47 \\
1.50 \\
1.48 \\
1.41 \\
1.46\end{array}$ & $\begin{array}{l}1.62 \\
1.55 \\
1.52 \\
1.54 \\
1.40 \\
1.55\end{array}$ & & \\
\hline & $\begin{array}{r}8 \\
8 \\
9 \\
9 \\
11 \\
11\end{array}$ & $\begin{array}{l}2 \\
4 \\
2 \\
4 \\
2 \\
4\end{array}$ & $\begin{array}{c}112-115 \\
90-92 \\
111-114 \\
95-97 \\
133-136 \\
114-117\end{array}$ & $\begin{array}{l}1.66 \\
1.50 \\
1.57 \\
1.65 \\
1.58 \\
1.45\end{array}$ & $\begin{array}{l}1.64 \\
1.61 \\
1.62 \\
1.40 \\
1.54 \\
1.57\end{array}$ & & \\
\hline & $\begin{array}{l}12 \\
12 \\
13 \\
17 \\
18 \\
19\end{array}$ & $\begin{array}{l}2 \\
4 \\
4 \\
6 \\
4 \\
4\end{array}$ & $\begin{array}{c}70-72 \\
112-115 \\
103-105 \\
35-38 \\
110 \\
83-87\end{array}$ & $\begin{array}{l}1.56 \\
1.39 \\
1.31 \\
1.30 \\
1.31 \\
1.31\end{array}$ & $\begin{array}{l}1.62 \\
1.52 \\
1.43 \\
1.30 \\
1.31 \\
1.34\end{array}$ & 149.83 & 114.5 \\
\hline & $\begin{array}{l}21 \\
22 \\
23 \\
26 \\
27 \\
28\end{array}$ & $\begin{array}{l}4 \\
4 \\
2 \\
2 \\
4 \\
3\end{array}$ & $\begin{array}{c}39-42 \\
96-98 \\
101 \\
75 \\
95-98 \\
89-92\end{array}$ & $\begin{array}{l}1.34 \\
1.85 \\
1.80 \\
1.84 \\
1.78 \\
1.93\end{array}$ & $\begin{array}{l}1.35 \\
1.85 \\
1.71 \\
1.87 \\
1.82 \\
1.88\end{array}$ & & \\
\hline & $\begin{array}{l}31 \\
38\end{array}$ & $\begin{array}{l}1 \\
2\end{array}$ & $\begin{array}{c}130-133 \\
6-8\end{array}$ & $\begin{array}{l}1.86 \\
1.96\end{array}$ & $\begin{array}{c}1.88 \\
-\end{array}$ & & \\
\hline \multirow[t]{3}{*}{184} & $\begin{array}{l}1 \\
1 \\
4 \\
6 \\
7 \\
9\end{array}$ & $\begin{array}{l}2 \\
3 \\
1 \\
4 \\
6 \\
6\end{array}$ & $\begin{array}{c}65-67 \\
29-32 \\
62-65 \\
131-134 \\
88-97 \\
104-107\end{array}$ & $\begin{array}{l}1.45 \\
1.44 \\
1.37 \\
1.49 \\
1.41 \\
1.52\end{array}$ & $\begin{array}{l}1.44 \\
1.52 \\
1.38 \\
1.52 \\
1.38 \\
1.56\end{array}$ & $\begin{array}{r}120.98 \\
86.59\end{array}$ & $\begin{array}{r}121.0 \\
81.1\end{array}$ \\
\hline & $\begin{array}{l}11 \\
12 \\
16 \\
17 \\
18 \\
19\end{array}$ & $\begin{array}{l}4 \\
2 \\
2 \\
2 \\
2 \\
2\end{array}$ & $\begin{array}{c}112-115 \\
40 \\
89-92 \\
130-133 \\
100-103 \\
68-70\end{array}$ & $\begin{array}{l}1.59 \\
1.53 \\
1.38 \\
1.37 \\
1.38 \\
1.44\end{array}$ & $\begin{array}{l}1.60 \\
1.45 \\
1.40 \\
1.44 \\
1.38 \\
1.46\end{array}$ & & \\
\hline & $\begin{array}{l}20 \\
21 \\
22\end{array}$ & $\begin{array}{l}2 \\
3 \\
2\end{array}$ & $\begin{array}{c}134-137 \\
118-121 \\
92-95\end{array}$ & $\begin{array}{l}1.38 \\
1.49 \\
1.51\end{array}$ & $\begin{array}{l}1.40 \\
1.49 \\
1.37\end{array}$ & & \\
\hline $184 \mathrm{~B}$ & $\begin{array}{l}5 \\
5\end{array}$ & $\begin{array}{l}3 \\
3\end{array}$ & $\begin{array}{c}50 \\
100\end{array}$ & $\begin{array}{l}1.99 \\
1.97\end{array}$ & $\overline{1.64}$ & & \\
\hline 185 & $\begin{array}{r}4 \\
5 \\
6 \\
7 \\
8 \\
10 \\
17 \\
19\end{array}$ & $\begin{array}{l}6 \\
2 \\
1 \\
2 \\
2 \\
4 \\
2 \\
2\end{array}$ & $\begin{array}{c}127-129 \\
128-131 \\
131-134 \\
83-85 \\
113-116 \\
131-133 \\
139-141 \\
41-44\end{array}$ & $\begin{array}{l}1.49 \\
1.41 \\
1.53 \\
1.42 \\
1.49 \\
1.48 \\
1.63 \\
1.68\end{array}$ & $\begin{array}{l}1.46 \\
1.44 \\
\overline{1.48} \\
1.50 \\
1.52 \\
1.34 \\
1.47\end{array}$ & $\begin{array}{l}87.47 \\
78.23\end{array}$ & $\begin{array}{l}84.2 \\
85.9\end{array}$ \\
\hline 185 & $\begin{array}{l}19 \\
23\end{array}$ & $\begin{array}{l}2 \\
2\end{array}$ & $\begin{array}{l}50 \\
75\end{array}$ & $\begin{array}{l}1.69 \\
1.65\end{array}$ & $\begin{array}{l}1.43 \\
1.51\end{array}$ & & \\
\hline \multirow[t]{2}{*}{186} & $\begin{array}{l}2 \\
3 \\
4 \\
6 \\
7 \\
8\end{array}$ & $\begin{array}{l}1 \\
3 \\
1 \\
2 \\
2 \\
1\end{array}$ & $\begin{array}{c}66-69 \\
39-42 \\
31-33 \\
128-131 \\
64-66 \\
76-79\end{array}$ & $\begin{array}{l}1.50 \\
1.52 \\
1.55 \\
1.63 \\
1.60 \\
1.61\end{array}$ & $\begin{array}{l}1.50 \\
- \\
1.52 \\
1.42 \\
1.59 \\
1.56\end{array}$ & $\begin{array}{l}79.55 \\
77.35\end{array}$ & $\begin{array}{l}78.8 \\
76.1\end{array}$ \\
\hline & $\begin{array}{l}8 \\
9\end{array}$ & $\begin{array}{l}3 \\
6\end{array}$ & $\begin{array}{l}100-102 \\
138-141\end{array}$ & $\begin{array}{l}1.74 \\
1.65\end{array}$ & $\begin{array}{l}1.62 \\
1.40\end{array}$ & & \\
\hline
\end{tabular}


TABLE 1 - Continued

\begin{tabular}{|c|c|c|c|c|c|c|c|}
\hline Hole & Core & Section & Interval & $\begin{array}{l}\text { Shore Lab. } \\
\text { Density } \\
(\mathrm{g} / \mathrm{cc})\end{array}$ & $\begin{array}{c}\text { GRAPE } \\
\text { Density } \\
(\mathrm{g} / \mathrm{cc})\end{array}$ & $\begin{array}{l}\text { Shore Lab. } \\
\text { Water Content } \\
\text { (\% dry wt.) }\end{array}$ & $\begin{array}{c}\text { Syringe } \\
\text { Water Content } \\
\text { (\% dry wt.) }\end{array}$ \\
\hline & 10 & 2 & $66-69$ & 1.76 & 1.64 & 53.90 & 51.3 \\
\hline & 11 & 4 & $36-39$ & 1.75 & 1.67 & & \\
\hline & 17 & 2 & $119-121$ & 1.71 & 1.28 & & \\
\hline & 18 & 2 & 25 & 1.73 & 1.38 & & \\
\hline & 19 & 2 & $81-84$ & 1.79 & - & & \\
\hline & 19 & 4 & $99-101$ & 1.84 & 1.75 & & \\
\hline & 20 & 4 & $59-62$ & 1.76 & 1.54 & & \\
\hline & 21 & 2 & $110-112$ & 1.83 & 1.61 & & \\
\hline & 21 & 3 & 30 & 1.85 & 1.54 & & \\
\hline & 23 & 3 & $102-105$ & 1.75 & 1.41 & & \\
\hline & 24 & 1 & 20 & 1.80 & 1.30 & & \\
\hline & 24 & 1 & $40-42$ & 1.88 & 1.19 & & \\
\hline & 25 & 1 & 50 & 1.76 & 1.49 & & \\
\hline & 25 & 1 & $50-53$ & 1.81 & 1.49 & & \\
\hline & 26 & 2 & $117-119$ & 1.84 & 1.67 & & \\
\hline & 27 & 1 & 30 & 1.86 & 1.53 & & \\
\hline & 27 & 2 & 40 & 1.88 & 1.41 & & \\
\hline & 27 & 2 & $143-144$ & 1.97 & 1.44 & & \\
\hline & 27 & 3 & 30 & 1.89 & 1.19 & & \\
\hline & 27 & 4 & 100 & 1.83 & 1.52 & & \\
\hline & 27 & 6 & 75 & 1.79 & 1.49 & & \\
\hline & 28 & 4 & $109-112$ & 1.90 & 1.58 & & \\
\hline & 28 & 4 & 130 & 1.89 & 1.60 & & \\
\hline \multirow[t]{3}{*}{187} & 2 & 1 & $89-91$ & 1.76 & 1.70 & & \\
\hline & 2 & 2 & $87-90$ & 1.63 & 1.43 & & \\
\hline & 4 & 2 & $128-130$ & 1.90 & 1.72 & & \\
\hline \multirow[t]{16}{*}{188} & 1 & 1 & $128-130$ & 1.32 & - & 150.59 & 144.6 \\
\hline & 2 & 1 & $38-40$ & 1.37 & - & 126.15 & 149.4 \\
\hline & 3 & 1 & $35-38$ & 1.43 & 1.37 & & \\
\hline & 3 & 2 & $38-41$ & 1.45 & - & 94.82 & 91.2 \\
\hline & 3 & 3 & $114-116$ & 1.45 & 1.60 & & \\
\hline & 3 & 4 & $41-43$ & 1.39 & 1.40 & & \\
\hline & 4 & 3 & $61-63$ & 1.30 & - & 160.79 & 17.3 .0 \\
\hline & 6 & 2 & $92-95$ & 1.36 & 1.46 & & \\
\hline & 6 & 3 & $35-37$ & 1.44 & 1.47 & 92.63 & 100.0 \\
\hline & 7 & 1 & $31-34$ & 1.23 & 1.26 & 205.28 & 200.0 \\
\hline & 7 & 2 & $18-20$ & 1.26 & 1.29 & & \\
\hline & 7 & 6 & $86-89$ & 1.28 & 1.34 & & \\
\hline & 8 & 1 & $15-18$ & 1.36 & 1.40 & 118.82 & 97.3 \\
\hline & 8 & 4 & $70-73$ & 1.32 & 1.32 & & \\
\hline & 9 & 1 & $54-56$ & 1.26 & 1.31 & & \\
\hline & 9 & 2 & $10-12$ & 1.20 & 1.29 & & \\
\hline \multirow[t]{9}{*}{189} & 3 & 1 & $36-38$ & 1.58 & 1.55 & & \\
\hline & 3 & 4 & $14-16$ & 1.56 & 1.55 & & \\
\hline & 4 & 3 & $36-39$ & 1.57 & 1.53 & & \\
\hline & 4 & 4 & $47-49$ & 1.56 & 1.58 & & \\
\hline & 5 & 3 & $117-119$ & 1.65 & 1.31 & & \\
\hline & 5 & 4 & $84-87$ & 1.55 & 1.41 & & \\
\hline & 6 & 2 & $2-6$ & 1.58 & 1.59 & & \\
\hline & 7 & 3 & $140-143$ & 1.58 & 1.49 & & \\
\hline & 10 & 1 & $123-126$ & 1.94 & 1.87 & & \\
\hline \multirow[t]{12}{*}{190} & 1 & 1 & $137-140$ & 1.47 & - & 95.58 & 96.0 \\
\hline & 1 & 2 & $68-71$ & 1.53 & 1.56 & 82.37 & 82.3 \\
\hline & 2 & 1 & $140-142$ & 1.53 & 1.47 & 83.4 & 74.3 \\
\hline & 2 & 2 & $15-17$ & 1.57 & 1.53 & 72.5 & 69.5 \\
\hline & 3 & 2 & $139-142$ & 1.51 & 1.50 & 86.8 & 87.3 \\
\hline & 3 & 3 & $124-126$ & 1.57 & 1.57 & & \\
\hline & 3 & 4 & $43-45$ & 1.55 & 1.53 & & \\
\hline & 4 & 2 & $27-29$ & 1.55 & 1.50 & 77.0 & 77.2 \\
\hline & 4 & 3 & $122-125$ & 1.47 & 1.46 & & \\
\hline & 4 & 4 & $60-63$ & 1.47 & 1.38 & & \\
\hline & 5 & 4 & $116-119$ & 1.62 & 1.51 & & \\
\hline & 5 & 5 & $100-103$ & 1.46 & 1.45 & 99.17 & 87.7 \\
\hline
\end{tabular}


TABLE 1 - Continued

\begin{tabular}{|c|c|c|c|c|c|c|c|}
\hline Hole & Core & Section & Interval & $\begin{array}{l}\text { Shore Lab. } \\
\text { Density } \\
(\mathrm{g} / \mathrm{cc})\end{array}$ & $\begin{array}{c}\text { GRAPE } \\
\text { Density } \\
\text { (g/cc) }\end{array}$ & $\begin{array}{l}\text { Shore Lab. } \\
\text { Water Content } \\
\text { (\% dry wt.) }\end{array}$ & $\begin{array}{c}\text { Syringe } \\
\text { Water Content } \\
\text { (\% dry wt.) }\end{array}$ \\
\hline & 5 & 6 & $43-45$ & 1.52 & 1.51 & & \\
\hline & 6 & 4 & $79-81$ & 1.53 & 1.49 & 82.17 & 88.5 \\
\hline & 6 & 5 & $30-33$ & 1.53 & 1.52 & & \\
\hline & 7 & 1 & $26-28$ & 1.51 & 1.51 & & \\
\hline & 7 & 2 & $137-139$ & 1.64 & 1.62 & & \\
\hline & 7 & 3 & $27-30$ & 1.54 & 1.60 & 79.11 & 71.6 \\
\hline & 7 & 4 & $97-99$ & 1.54 & 1.59 & & \\
\hline & 8 & 2 & $11-13$ & 1.57 & 1.57 & & \\
\hline & 8 & 3 & $49-52$ & 1.51 & 1.50 & & \\
\hline & 8 & 4 & $34-36$ & 1.61 & 1.64 & 66.38 & 78.4 \\
\hline & 8 & 5 & $90-92$ & 1.59 & 1.57 & & \\
\hline & 9 & 2 & $74-76$ & 1.62 & 1.55 & & \\
\hline & 9 & 3 & $17-19$ & 1.63 & 1.61 & & \\
\hline & 10 & 2 & $110-113$ & 1.41 & 1.39 & & \\
\hline & 10 & 3 & 81-84 & 1.42 & 1.45 & & \\
\hline & 11 & 2 & $79-82$ & 1.52 & 1.53 & & \\
\hline & 11 & 3 & $109-112$ & 1.51 & 1.54 & & \\
\hline & 11 & 4 & $57-59$ & 1.46 & 1.46 & & \\
\hline & 11 & 5 & $81-83$ & 1.37 & 1.37 & & \\
\hline & 12 & 4 & $80-82$ & 1.49 & 1.56 & & \\
\hline & 13 & 2 & $49-51$ & 1.34 & 1.63 & & \\
\hline & 14 & 2 & $73-75$ & 1.36 & 1.42 & & \\
\hline & 14 & 6 & $69-71$ & 1.36 & 1.41 & & \\
\hline \multirow[t]{14}{*}{191} & 2 & 2 & $22-23$ & 1.35 & - & 137.25 & 132.6 \\
\hline & 4 & 1 & $33-35$ & 1.49 & 1.33 & & \\
\hline & 4 & 3 & $79-81$ & 1.44 & 1.32 & & \\
\hline & 4 & 4 & $91-93$ & 1.46 & 1.33 & & \\
\hline & 4 & 6 & $140-142$ & 1.53 & 1.47 & & \\
\hline & 5 & 1 & $97-99$ & 1.71 & 1.66 & & \\
\hline & 5 & 2 & $75-77$ & 1.74 & - & 48.11 & 47.9 \\
\hline & 5 & 3 & $101-104$ & 1.69 & 1.65 & & \\
\hline & 5 & 4 & $94-96$ & 1.74 & 1.68 & & \\
\hline & 5 & 5 & $116-119$ & 1.76 & 1.66 & & \\
\hline & 6 & 2 & $103-105$ & 1.67 & 1.60 & & \\
\hline & 7 & 2 & $141-142$ & 1.80 & 1.62 & & \\
\hline & 8 & 2 & 98-101 & 1.71 & 1.65 & & \\
\hline & 9 & 1 & 90 & 1.78 & 1.32 & & \\
\hline \multirow[t]{6}{*}{$191 \mathrm{~A}$} & 1 & 4 & $137-138$ & 1.57 & 1.52 & & \\
\hline & 2 & 1 & $114-117$ & 1.57 & - & 71.75 & 91.7 \\
\hline & 2 & 2 & $73-76$ & 1.43 & 1.38 & & \\
\hline & 2 & 3 & $113-115$ & 1.50 & 1.60 & & \\
\hline & 4 & 5 & $32-35$ & 1.53 & 1.43 & 80.09 & 58.1 \\
\hline & 4 & 6 & $57-60$ & 1.65 & 1.53 & & \\
\hline \multirow[t]{3}{*}{ 191B } & 1 & 2 & $131-134$ & 1.44 & 1.42 & & \\
\hline & 1 & 3 & $37-39$ & 1.41 & 1.43 & & \\
\hline & 1 & 6 & $98-101$ & 1.49 & 1.53 & & \\
\hline \multirow[t]{18}{*}{192} & 1 & 1 & $68-70$ & 1.41 & - & 115.57 & 119.2 \\
\hline & 2 & 2 & $137-140$ & 1.46 & 1.44 & & \\
\hline & 2 & 4 & $104-106$ & 1.50 & 1.43 & & \\
\hline & 3 & 1 & $82-85$ & 1.48 & 1.41 & 91.12 & 84.3 \\
\hline & 3 & 2 & $65-67$ & 1.56 & 1.56 & & \\
\hline & 3 & 3 & $53-55$ & 1.57 & 1.60 & & \\
\hline & 3 & 4 & $115-118$ & 1.49 & - & & \\
\hline & 4 & 1 & $52-55$ & 1.48 & 1.54 & 92.90 & 88.0 \\
\hline & 4 & 2 & $46-48$ & 1.57 & 1.61 & & \\
\hline & 4 & 3 & $85-88$ & 1.48 & 1.46 & & \\
\hline & 4 & 4 & $51-54$ & 1.55 & 1.58 & & \\
\hline & 4 & 5 & $23-26$ & 1.56 & 1.54 & & \\
\hline & 4 & 6 & $20-22$ & 1.54 & 1.50 & 77.14 & 81.0 \\
\hline & 5 & 1 & $89-91$ & 1.45 & 1.51 & & \\
\hline & 5 & 2 & $32-34$ & 1.55 & 1.55 & & \\
\hline & 5 & 3 & $16-18$ & 1.47 & 1.41 & & \\
\hline & 5 & 4 & $99-102$ & 1.51 & 1.53 & 83.95 & 89.9 \\
\hline & 5 & 5 & $7-10$ & 1.51 & 1.50 & & \\
\hline
\end{tabular}


TABLE 1 - Continued

\begin{tabular}{|c|c|c|c|c|c|c|c|}
\hline Hole & Core & Section & Interval & $\begin{array}{l}\text { Shore Lab. } \\
\text { Density } \\
(\mathrm{g} / \mathrm{cc})\end{array}$ & $\begin{array}{c}\text { GRAPE } \\
\text { Density } \\
\text { (g/cc) }\end{array}$ & $\begin{array}{l}\text { Shore Lab. } \\
\text { Water Content } \\
\text { (\% dry wt.) }\end{array}$ & $\begin{array}{c}\text { Syringe } \\
\text { Water Content } \\
\text { (\% dry wt.) }\end{array}$ \\
\hline & 6 & 2 & $143-145$ & 1.39 & - & 109.04 & 112.1 \\
\hline & 7 & 1 & $134-137$ & 1.49 & 1.51 & & \\
\hline & 7 & 2 & $88-91$ & 1.57 & 1.59 & 71.08 & 75.0 \\
\hline & 7 & 3 & $87-89$ & 1.55 & 1.55 & & \\
\hline & 7 & 4 & $104-106$ & 1.49 & 1.50 & & \\
\hline & 8 & 5 & $35-38$ & 1.51 & 1.49 & & \\
\hline & 8 & 6 & $88-90$ & 1.52 & 1.46 & 81.63 & 77.1 \\
\hline & 9 & 3 & $85-87$ & 1.48 & 1.45 & & \\
\hline & 9 & 4 & $49-52$ & 1.47 & 1.47 & & \\
\hline & 9 & 5 & $9-11$ & 1.55 & 1.54 & 74.90 & 71.4 \\
\hline & 9 & 6 & $120-123$ & 1.53 & 1.55 & & \\
\hline & 10 & 3 & $13-16$ & & & 104.67 & 104.9 \\
\hline & 12 & 1 & $77-79$ & 1.39 & 1.41 & & \\
\hline & 12 & 2 & $41-43$ & 1.39 & 1.43 & & \\
\hline & 12 & 3 & $57-59$ & 1.39 & 1.41 & 109.03 & 105.7 \\
\hline & 12 & 4 & $44-46$ & 1.37 & 1.38 & & \\
\hline & 13 & 2 & $66-68$ & 1.30 & 1.26 & & \\
\hline & 13 & 3 & $44-46$ & 1.37 & 1.38 & & \\
\hline & 13 & 5 & $119-121$ & 1.36 & 1.36 & & \\
\hline & 15 & 4 & 29-31 & 1.41 & 1.40 & & \\
\hline & 15 & 4 & $93-95$ & 1.41 & 1.41 & 106.55 & 101.2 \\
\hline & 17 & 3 & $139-141$ & 1.41 & 1.45 & & \\
\hline & 19 & 2 & $60-63$ & 1.41 & 1.44 & 105.53 & 96.9 \\
\hline & 21 & 2 & $131-133$ & 1.39 & 1.39 & & \\
\hline & 21 & 1 & 125 & 1.36 & 1.28 & & \\
\hline & 25 & 2 & 70 & 1.44 & 1.39 & & \\
\hline \multirow[t]{6}{*}{$192 \mathrm{~A}$} & 5 & 1 & 40 & 2.16 & 1.80 & & \\
\hline & 5 & 1 & 130 & 2.82 & 2.31 & & \\
\hline & 5 & 2 & 40 & 2.61 & 2.33 & & \\
\hline & 5 & 3 & 135 & 2.72 & 2.13 & & \\
\hline & 5 & 4 & 140 & 2.63 & 2.11 & & \\
\hline & 5 & 5 & 35 & 2.61 & 2.31 & & \\
\hline \multirow[t]{14}{*}{193} & 1 & 1 & $114-116$ & 1.43 & 1.42 & & \\
\hline & 1 & 1 & $136-138$ & 1.40 & 1.40 & 115.46 & 97.4 \\
\hline & 1 & 2 & $96-98$ & 1.49 & 1.42 & 88.85 & 93.5 \\
\hline & 2 & 1 & $107-108$ & 1.39 & 1.39 & 119.28 & 107.0 \\
\hline & 2 & 3 & $107-109$ & 1.49 & 1.51 & 87.49 & 91.2 \\
\hline & 3 & 1 & $131-134$ & 1.49 & 1.42 & & \\
\hline & 3 & 2 & $95-97$ & 1.45 & 1.50 & & \\
\hline & 3 & 2 & $105-108$ & 1.50 & 1.56 & 86.36 & 83.4 \\
\hline & 3 & 3 & 48-51 & 1.38 & 1.42 & & \\
\hline & 3 & 3 & $96-98$ & 1.49 & 1.57 & & \\
\hline & 3 & 4 & $70-73$ & 1.50 & 1.52 & 85.33 & 90.2 \\
\hline & 3 & 4 & $124-126$ & 1.44 & 1.49 & & \\
\hline & 3 & 5 & $71-74$ & 1.43 & 1.44 & 105.68 & 86.2 \\
\hline & 3 & 5 & $125-128$ & 1.54 & 1.51 & & \\
\hline
\end{tabular}

\section{CONCLUSIONS}

1. All Deep Sea Drilling Project cores are disturbed from an engineering point of view. Engineering properties (with the possible exception of density) obtained from samples of these cores are not representative of the in situ condition. Correction procedures must be used to estimate in situ behavior.

2. Previous research has shown that shear strength may be corrected for disturbance using the residual pressure maintained by the sample pore water. These residual pore pressures were measured during Leg 19 and an approximate technique for using them to estimate in situ strength was developed. The estimated in situ strengths increase with overburden at rates which are typical of normally consolidated soils (around 0.3 ). There is only moderate variation (plus or minus 50\%) among the sites and among the sediment types.

The estimated strength of the material more shallow than 30 meters was always significantly greater relative to overburden than that of the more deeply embedded material. Possibly a form of interparticle bonding which is independent of overburden pressure dominates over this region.

3. One triaxial test performed on a diatomaceous silty clay sample yielded a typical drained friction angle of 35 degrees. The strength to overburden pressure ratio obtained from the triaxial test was 0.37 . Using the proposed residual 
TABLE 2

Comparison of Density and Water Content Measurements-Average Values

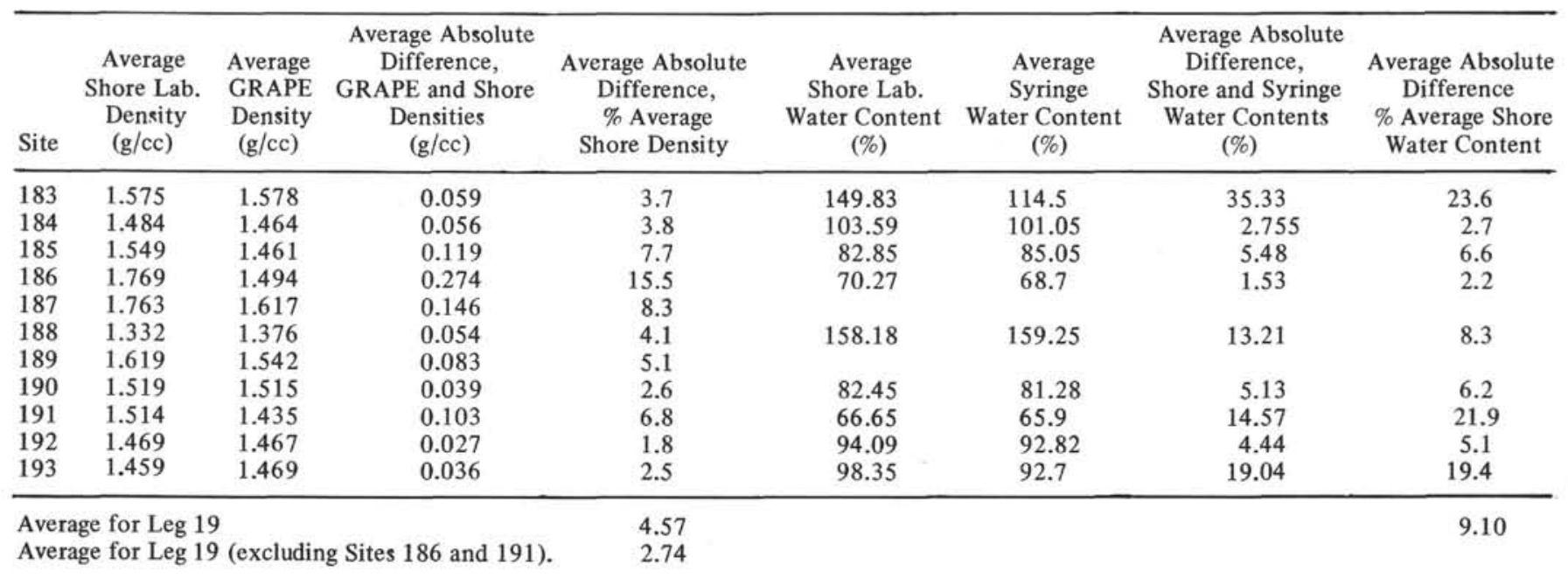

pore pressure method of estimating in situ shear strength, a value of 0.34 was obtained. This close compliance lends additional credibility to the proposed procedure.

4. In general, the observed shear strength behavior was not unusual for a normally consolidated material. One possible engineering problem which was observed, however, was the ease with which the diatom oozes could be liquified.

5. Consolidation (equivalent to compaction in geologic terms) was investigated through laboratory testing of samples and consideration of void ratio variation with in situ overburden pressure (field curve). For the silty clays it was found that the field data closely approximated previously obtained data on highly colloidal clays. The one laboratory test on silty clay produced a consolidation curve which, when corrected for disturbance, also agreed well with the field data and the previously obtained data. No cementation or time effects were evident.

6. The diatom ooze data differed from any previously obtained data. Extremely high void ratios existed at great embedment depths. The laboratory consolidation test data indicated that the materials was compressible at very high stresses. However, an artificially sedimented sample study showed that the material was almost incompressible at low stresses. Grain crushing at the higher stresses was hypothesized as a possible explanation for this behavior.

7. Using the standard Casagrande (1936) construction, it was determined that all of the samples which were subjected to consolidation tests were normally consolidated, i.e., had never been subjected to stresses greater than the present in situ stresses.

8. The Gamma Ray Attenuation Porosity Evaluation (GRAPE) provides a good estimate (plus or minus $2.5 \%$ ) of the sample density. If the sample contains gases, care should be taken in extrapolating results back to the in situ condition. The shipboard syringe produces results which may be in error by an average of 10 percent.

\section{REFERENCES}

Bennett, R. H., Lambert, D. N. and Grim, P. J., 1971. Tables for determining unit weight of deep sea sediments from water content and average grain density measurements. NOAA Tech. Mem. ERL ADML-13.

Bishop, A. W. and Henkel, D. J., 1962. The Measurement of Soil Properties in the Triaxial Test. London (Edward Arnold Ltd.). 2nd Ed.

Bjerrum, L. and Simons, N., 1960. Comparison of shear strength characteristics of normally consolidated clays. ASCE Con. Shear Strength of Cohesive Soil. Boulder, Colorado. 711.

Brand, E. W., 1967. The vane shear test and its use for strength measurement of cohesive soils. RILEM Bull. 36, 191.

Casagrande, A., 1936. The determination of the preconsolidation load and its practical significance. Proc. First Intern. Conf. Soil Mech. Found. Engineering. Cambridge, Massachusetts. 60 .

Edgar, N. T., Saunders, J. B. et al., in preparation. Initial Reports of the Deep Sea Drilling Project, Volume XV. Washington (U. S. Government Printing Office).

Evans, H. B., 1965. GRAPE - A device for continuous determination of material density and porosity. Trans. 6th Ann. SPWLA Logging Sympo. Dallas, Texas. II, B1.

Gibbs, H. J. and Coffey, C. T., 1969. Application of pore Pressure Measurements to Shear Strength of Cohesive Soils. U. S. Bur. Reclamation Rept. No. EM-761. Denver, Colorado.

Hamilton, E. L., 1964. Consolidation characteristics and related properties of sediments from Experimental Mohole (Guadalupe Site), J. Geophys. Res. 69 (20), 4257.

Harms, J. C. and Choquette, P. W., 1965. Geologic evaluation of a gamma-ray porosity device. Trans. 6th Ann. SPWLA Logging Sympo. Dallas, Texas. VII, Cl.

Hironaka, M. C., 1966. Engineering Properties of Marine Sediments Near San Miguel Island, California. U. S. Naval Civil Engineering Lab. Tech. Rep. R-503.

Hvorslev, M. J., 1949. Subsurface exploration and sampling of soils for civil engineering purposes. Rep. Comm. Sampling and Testing, Soil Mech. and Found. Div., Am. Soc. Civil Engrs.

Ladd, C. C. and Lambe, T. W., 1963. The strength of "undisturbed" clay determined from undrained tests. ASTM Standard Tech. Pub. 361, 342.

Lambe, T. W. and Whitman, R. V., 1969. Soil Mechanics. New York (John Wiley and Sons), 127. 
Lee, H. J., in press. In-situ strength of sea floor soil determined from tests on partially disturbed cores. U. S. Naval Civil Engineering Lab. Tech. Rept.

Leonards, G. A. and Altschaeffl, A. G., 1964. Compressibility of clay. J. Soil Mech. and Founda. Div., Am. Soc. Civil Engrs.

Migliore, H. J. and Lee, H. J., 1971. Seafloor Penetration Tests: Presentation and Analysis of Results. U. S. Naval Civil Engineering Lab. Tech. Note N-1178.
Peterson, M. N. A., Edgar, N. T. et al., 1970. Initial Reports of the Deep Sea Drilling Project, Volume II. Washington (U. S. Government Printing Office).

Schmertmann, J. M., 1955. The undisturbed consolidation of clay. Trans. Am. Soc. Civil Engrs. 120, 1201.

Taylor, D. W., 1948. Fundamentals of Soil Mechanics. New York (John Wiley and Sons).

Terzaghi, K., 1943. Theoretical Soil Mechanics. New York (John Wiley and Sons). 